\title{
Durability of Electrocatalysts for ORR: Pt on Nanocomposite of Reduced Graphene Oxide with FTO versus Pt/C
}

\author{
Dana Schonvogel, $\oplus^{1,2, \mathrm{z}}$ Julia Hülstede, ${ }^{1,2}$ Peter Wagner, ${ }^{1, *}$ Alexander Dyck, ${ }^{1, *}$ \\ Carsten Agert, ${ }^{1}$ and Michael Wark ${ }^{2}$
}

\author{
${ }^{1}$ DLR Institute of Networked Energy Systems, 26129 Oldenburg, Germany \\ ${ }^{2}$ Institute of Chemistry, Carl von Ossietzky University, 26129 Oldenburg, Germany
}

\begin{abstract}
Catalyst degradation results in performance losses of proton exchange membrane fuel cells (PEMFC) and is caused by electrochemical instability of commonly used platinum on carbon black $(\mathrm{Pt} / \mathrm{C})$. In this study, a comparison in durability of commercial $\mathrm{Pt} / \mathrm{C}$ with a new Pt catalyst on a nanocomposite of fluorine-doped $\mathrm{SnO}_{2}$ (FTO) and reduced graphene oxide (rGO) is carried out. Transmission electron microscopy (TEM) shows similar Pt distributions on support surfaces and Pt particle sizes so that a high comparability of support materials during durability investigation is ensured. High resolution TEM with EDS reveals dispersed Pt anchored at FTO-rGO interfaces. During stripping voltammetry Pt/FTO-rGO provides weaker CO sorption than $\mathrm{Pt} / \mathrm{C}$, indicating higher $\mathrm{CO}$ tolerances. Accelerated stress testing (0.05-1.47 $\left.\mathrm{V}_{\mathrm{RHE}}\right)$ provokes Pt degradation on both supports in comparable rates. However, the FTO-rGO nanocomposite presents the more stable substrate in this study compared to carbon black. Identical location TEM illustrates stable FTO particles in size and position on rGO surface. Moreover, unchanged hydroquinone/quinone (HQ/Q) amounts and double layer capacitance in case of Pt/FTO-rGO were revealed by cyclic voltammetry. On the contrary, standard Pt/C shows significantly more generation of HQ/Q functionalities by a factor of 25 and thus higher carbon corrosion.

(C) The Author(s) 2018. Published by ECS. This is an open access article distributed under the terms of the Creative Commons Attribution 4.0 License (CC BY, http://creativecommons.org/licenses/by/4.0/), which permits unrestricted reuse of the work in any medium, provided the original work is properly cited. [DOI: 10.1149/2.0361806jes]

(cc) BY

Manuscript submitted November 30, 2017; revised manuscript received April 19, 2018. Published May 8, 2018. This was Paper 1579 presented at the National Harbor, Maryland Meeting of the Society, October 1-5, 2017. This paper is part of the JES Focus Issue on Proton Exchange Membrane Fuel Cell (PEMFC) Durability.
\end{abstract}

Proton exchange membrane fuel cells (PEMFCs) are attractive for stationary, automotive and portable applications, but PEMFCs still show a loss of performance during cell operation. ${ }^{1-3}$ Chemical, electrochemical, physical, thermal and also mechanical processes result in the aging of fuel cell components like catalyst and membrane., ${ }^{2,4-6}$ Especially the fuel cell catalyst - commonly consisting of platinum supported on carbon black $(\mathrm{Pt} / \mathrm{C})$ - shows degradation under PEMFC conditions at low $\mathrm{pH}$ values and cell voltages up to $1.4 \mathrm{~V}$ during startstop operation. ${ }^{7}$ Pt nanoparticles can dissolve and then agglomerate to larger particles or leave the cell with the FC product water. ${ }^{4,8} \mathrm{Pt}$ ions can also diffuse into the membrane and react to electrically isolated platinum. ${ }^{9}$ Additionally, corrosion of the carbon support during cell operation leads to detachment of Pt particles. ${ }^{10,11}$ Electrochemical instability of carbon starts from $0.207 \mathrm{~V}_{\mathrm{SHE}}{ }^{2}$ and gets relevant in PEMFCs from a cell voltage of $0.9 \mathrm{~V}_{\mathrm{SHE}} \cdot{ }^{12} \mathrm{In}$ sum, these different catalyst aging processes change platinum and support structure significantly and limit the durability of the whole fuel cell. To achieve higher PEMFC lifetimes, research on alternative support materials for the platinum catalyst is indispensable.

On the one hand, graphene-based carbon has received much attention in the last decade as support material in fuel cells. ${ }^{13-18}$ Reduced graphene oxide (rGO) is characterized by wrinkled single sheets and defect sites for interaction with nanoparticles like platinum. ${ }^{19,20}$ On the other hand, mixed metal oxides like indium tin oxide (ITO) have some suitable properties with respect to durability issues in PEMFCs like the already oxidized stage ${ }^{21}$ and the almost stable characteristics in strong acidic environments and enhanced temperatures. ${ }^{22}$ Liu et al. ${ }^{23}$ showed high durability of platinum on ITO nanoparticles as ORR electrocatalyst in contrast to $\mathrm{Pt} / \mathrm{C}$ (1000 triangle-wave cycles, $\left.0.0-1.4 \mathrm{~V}_{\mathrm{RHE}}\right)$. However, Schmies et al. ${ }^{24}$ recently reported partial dissolution of ITO crystals during potential cycling (5000 trianglewave cycles) between $0.60-0.95 \mathrm{~V}_{\mathrm{RHE}}$ with excellent ITO stability after cycling at higher potential range between 1.0-1.5 $\mathrm{V}_{\mathrm{RHE}}$. Next to ITO, further doped metal oxides have been studied toward supporting platinum in ORR catalysis. Dopants for $\mathrm{SnO}_{2}$ are $\mathrm{Nb}, \mathrm{W}$ or Ta revealing highest specific ORR activity in case of $\mathrm{Pt} / \mathrm{Nb}-\mathrm{SnO}_{2} .{ }^{25}$ With

\footnotetext{
*Electrochemical Society Member.
}

${ }^{\text {z}}$ E-mail: dana.schonvogel@dlr.de regard to stability, Kakinuma et al. ${ }^{26}$ verified enhanced durability of $\mathrm{Pt} / \mathrm{Nb}-\mathrm{SnO}_{2}$ and $\mathrm{Pt} / \mathrm{Sb}-\mathrm{SnO}_{2}$ compared to $\mathrm{Pt} / \mathrm{C}$ after potential step cycling (30 s at $0.9 \mathrm{~V}_{\mathrm{RHE}}, 30 \mathrm{~s}$ at $1.3 \mathrm{~V}_{\mathrm{RHE}}$ ). Durability comparison (cyclic voltammetry, 60000 cycles, $1.0-1.5 \mathrm{~V}_{\mathrm{RHE}}$ ) of other metal oxides for PEMFC application like $\mathrm{MoO}_{3}, \mathrm{SnO}_{2}, \mathrm{Nb}_{2} \mathrm{O}_{5}, \mathrm{Ta}_{2} \mathrm{O}_{5}, \mathrm{TiO}_{2}$, and $\mathrm{WO}_{3}$ showed most durable performance in case of $\mathrm{Pt} / \mathrm{SnO}_{2}{ }^{27}$

A further approach for enhanced Pt catalyst durability presented the application of an ITO-rGO nanocomposite. Kou et al. ${ }^{28}$ showed the formation of Pt-ITO-rGO interfaces and demonstrated by simulations through density functional theory an enhanced catalyst stability in comparison to carbon supports. However, indium is one of the worldwide rare metals, and platinum catalysts containing ITO would result in increased costs in fuel cell production compared to conventional Pt on carbon black. Thus, fluorine-doped tin (IV) oxide (FTO) represents the cheaper metal oxide regarding costs of materials in contrast to ITO ${ }^{29}$ FTO nanoparticles on rGO have already been studied as anode material in lithium ion batteries. Xu et al. ${ }^{30}$ measured capacity and resistance of FTO-rGO in $\mathrm{Li}$ ion batteries compared with only FTO, $\mathrm{SnO}_{2}-\mathrm{rGO}$ and only $\mathrm{SnO}_{2}$. The nanocomposite of FTO-rGO achieved the highest capacity retention and lowest resistances after 200 charge-discharge cycles, showing a comparatively high electrochemical stability. With respect to direct methanol fuel cells (DMFCs), FTO composites have been investigated as anodic catalyst support. Guo et al. ${ }^{31}$ tested FTO nanoparticles on multi-walled carbon nanotubes (MWCNTs) and showed a positive effect of fluorine-doping on the activity for methanol oxidation. Yang et al..$^{32}$ electrochemically reduced graphene oxide on an electrode consisting of FTO. Pt particles on this porous support demonstrated a higher methanol oxidation activity than Pt on solely the FTO electrode.

In this study, a nanocomposite with FTO nanoparticles on rGO has been investigated as cathodic Pt support for oxygen reduction reaction (ORR) in PEMFC application. The durability has been studied and compared to a standard Pt catalyst on Vulcan XC72. First, structural characterization of the Pt/FTO-rGO catalyst was performed using transmission electron microscopy (TEM), energy-dispersive X-ray spectroscopy (EDS), X-ray powder diffraction (XRD) and Xray photoelectron spectroscopy (XPS). Second, catalyst was deposited on a rotating disk electrode (RDE) and electrochemically investigated within a three-electrode setup. Accelerated stress testing (AST) in 
terms of potential cycling up to $1.47 \mathrm{~V}_{\mathrm{RHE}}$ in $\mathrm{O}_{2}$-saturated electrolyte was performed. Catalyst degradation was studied by determination of the electrochemical surface area (ECSA) and activity for the ORR before and after AST, whereas degradation of the support was evaluated by the detection of HQ/Q species and of the double layer capacitance. For verification, the commercial $\mathrm{Pt} / \mathrm{C}$ has been exposed to the same stability test by ensuring high comparability of the tested materials. Third, the AST was repeated using identical location TEM (IL-TEM) to optically reveal Pt degradation and to verify electrochemical results.

\section{Experimental}

Catalyst synthesis.-The Pt catalyst on FTO-rGO is prepared in four steps. Firstly, a modified Hummers method ${ }^{33}$ was used to chemically oxidize natural graphite (Graphit Kropfmühl GmbH, Germany). In a typical synthesis of graphene oxide, $1.0 \mathrm{~g}$ of graphite was given into $25 \mathrm{~mL}$ concentrated sulfuric acid (Carl Roth $\mathrm{GmbH}$ und Co. KG, Germany) and sonicated. After one hour, the mixture was cooled down to $0^{\circ} \mathrm{C}$ and $3.0 \mathrm{~g}$ potassium permanganate (Carl Roth $\mathrm{GmbH}$ und $\mathrm{Co}$. $\mathrm{KG}$, Germany) and $1.0 \mathrm{~g}$ sodium nitrate (Carl Roth $\mathrm{GmbH} \&$ Co. KG, Germany) were slowly added under stirring. Then, the mixture was stirred at $35^{\circ} \mathrm{C}$. After $18 \mathrm{~h}$, the flask was put into an ice bath and $80 \mathrm{~mL}$ water was quickly added, followed by dropping $10 \mathrm{~mL}$ hydrogen peroxide (30 wt $\%$, VWR International GmbH, Germany) into the solution. The mixture was washed and centrifuged with $10 \%$ hydrochloric acid and water to get a graphene oxide suspension in $\mathrm{H}_{2} \mathrm{O}$. Water was removed via centrifugation followed by rotary evaporation to obtain graphite oxide. Finally, the product was dried at $60^{\circ} \mathrm{C}$ for $48 \mathrm{~h}$ under vacuum. Secondly, graphite oxide was placed into a crucible filled with $\mathrm{Ar}$ and placed for $30 \mathrm{~s}$ in an oven with air atmosphere at $1050^{\circ} \mathrm{C}$. In this step, the material was exfoliated and thermally reduced to $\mathrm{rGO} .33,34$

In the third synthesis step, fluorine-doped tin (IV) oxide (FTO) nanoparticles were deposited on rGO sheets using a sol-gel method with hydrothermal treatment. $348 \mathrm{mg}$ tin (IV) chloride hydrate (Alfa Aesar $\mathrm{GmbH} \& \mathrm{Co} \mathrm{KG}$, Germany) and $50 \mathrm{mg}$ reduced graphene oxide were mixed in $60 \mathrm{~mL}$ water. After that, ammonium hydroxide $\left(28 \% \mathrm{NH}_{3}\right.$ in water, Alfa Aesar GmbH \& Co KG, Germany) was dropwise added until the mixture achieved $\mathrm{pH}$ 8. The obtained solid was filtrated under vacuum, washed with water and redispersed in $40 \mathrm{~mL} \mathrm{H} \mathrm{H}_{2} \mathrm{O} .73 .6 \mathrm{mg}$ ammonium fluoride (Alfa Aesar GmbH \& Co $\mathrm{KG}$, Germany) was added, before the mixture was transferred into an autoclave and stored at $180^{\circ} \mathrm{C}$ for $72 \mathrm{~h}$ to precipitate and crystallize FTO particles on rGO. Then, the product was filtrated under vacuum, washed with water and dried at $60^{\circ} \mathrm{C}$ for $48 \mathrm{~h}$ under vacuum. ${ }^{30,31}$

Finally, Pt nanoparticles were synthesized using chemical reduction of hexachloroplatinic acid (Thermo Fisher GmbH, Germany). $725 \mathrm{mg} \mathrm{H} \mathrm{H}_{2} \mathrm{PtCl}_{6} \bullet 6 \mathrm{H}_{2} \mathrm{O}$ were dissolved in $88 \mathrm{~mL}$ ethylene glycol (Carl Roth $\mathrm{GmbH}$ und Co. KG, Germany), serving as solvent and as reducing and nanoparticle stabilization agent. $12 \mathrm{~mL} 2 \mathrm{M} \mathrm{NaOH}$ in ethylene glycol was given to the solution to achieve $\mathrm{pH} 12$. The reduction to metallic $\mathrm{Pt}$ was done at $140^{\circ} \mathrm{C}$ for $4 \mathrm{~h}$ under stirring. The achieved Pt particle suspension was stored and provided for deposition on supports. To prepare the catalyst with $20 \mathrm{wt} \% \mathrm{Pt}$ nanoparticles on FTO-rGO, $1.6 \mathrm{~mL}$ of the previously prepared platinum suspension was washed and centrifuged with $1 \mathrm{M} \mathrm{HCl}$ to remove ethylene glycol. ${ }^{35}$ Then, Pt particles and $16 \mathrm{mg}$ FTO-rGO were mixed in acetone and sonicated until the solvent was evaporated and the final catalyst was remained. The product was dried at $60^{\circ} \mathrm{C}$ for $48 \mathrm{~h}$ under vacuum. ${ }^{28,36,37}$ Next to the obtained Pt/FTO-rGO, commercial $20 \mathrm{wt} \%$ platinum on Vulcan XC72 purchased from Sigma Aldrich Corporation (USA) has been investigated as reference.

Physical characterization.-TEM samples were prepared by suspending the catalyst in ethanol and placing a drop on a polyvinylformal coated $\mathrm{Cu}$ grid (200 mesh, Plano GmbH, Germany). After solvent evaporation, the catalyst coated grids were transferred into the TEM device for imaging. The EM 902A (Carl Zeiss AG, Germany) device with CCD camera and tungsten cathode with acceleration voltage of
Table I. Electrochemical parameters of RDE measurements.

\begin{tabular}{|c|c|c|c|c|c|}
\hline & Activation & $\mathrm{ECSA}_{\mathrm{HUPD}}$ & ECSA $_{\mathrm{CO}}$ & ORR & AST \\
\hline Start potential/ $\mathrm{V}_{\mathrm{RHE}}$ & 0.05 & 0.05 & 0.05 & 0.16 & 0.05 \\
\hline End potential/ $\mathrm{V}_{\mathrm{RHE}}$ & 1.47 & 1.00 & 1.10 & 1.05 & 1.47 \\
\hline Scan rate $/ \mathrm{mV} \mathrm{s}^{-1}$ & 500 & 50 & 50 & 5 & 500 \\
\hline No. of potential cycles & 100 & 3 & 3 & 3 & 1000 \\
\hline Electrolyte saturation & $\mathrm{N}_{2}$ & $\mathrm{~N}_{2}$ & $\mathrm{~N}_{2}$ & $\mathrm{O}_{2}$ & $\mathrm{O}_{2}$ \\
\hline
\end{tabular}

$80 \mathrm{kV}$ was used. High resolution TEM (HR-TEM) was carried out with JEM2100F (JEOL USA Inc, USA) equipped with the energydispersive X-ray spectroscopy (EDS) system INCA Energy TEM250 (Oxford Instruments plc, UK). EDS Spectra were detected with a $\mathrm{X}-\mathrm{Max} 80$ SDD-Detector and evaluated with INCA software.

$\mathrm{X}$-ray diffraction was performed using the EMPYREAN Series 2 device (PANalytical B.V., The Netherlands) with $\mathrm{Cu} \mathrm{K} \alpha$ X-ray source. Gonio scans were recorded in the $2 \theta$ range between $5^{\circ}$ and $90^{\circ}$ with $0.01^{\circ}$ steps. XP spectroscopy was carried out by use of the ESCALAB $250 \mathrm{Xi}$ (Thermo Fisher, UK) with $\mathrm{Al} \mathrm{K} \alpha$ radiation. Survey scans were recorded with $100 \mathrm{eV}$ pass energy, $20 \mathrm{~ms}$ dwell time, energy step sizes of $1 \mathrm{eV}$ and the averaging of 5 scans. High resolution scans were carried out with $10 \mathrm{eV}$ pass energy, $50 \mathrm{~ms}$ dwell time and energy step sizes of $0.02 \mathrm{eV}$. C1s, O1s, Sn3d and Pt4f scans were recorded five times and then averaged. The F1s region was scanned ten times because of expected small signals due to small doping amounts of fluorine. XPS analysis in terms of background correction and peak fitting was done using the software Advantage (v.5.932, Thermo Fisher, UK) with Smart background correction and Gauss-Lorentz line shape, respectively.

The real Pt loading in the catalyst was determined by mass spectrometry with inductive coupled plasma (ICP-MS, XSeries2, Thermo Fisher Scientific GmbH, Germany). $2.0 \mathrm{mg}$ of catalyst was digested in $1.6 \mathrm{~mL}$ hydrochloric acid with $1.2 \mathrm{~mL} \mathrm{HNO}_{3}$. The samples were filtered, diluted to a volume of $250 \mathrm{~mL}$ and further diluted by a factor of 5. Calibration was done using Pt concentrations of 100, 200, 400, 600 and $800 \mu \mathrm{g} \mathrm{L}^{-1}$ (platinum ICP standard solution, $1000 \mathrm{mg} \mathrm{L}^{-1}$, Carl Roth GmbH \& Co. KG, Germany) achieving a correlation coefficient of at least 0.999 . Lutetium in concentration of $1 \mathrm{mg} \mathrm{L}^{-1}$ served as internal standard. The recovery of $\mathrm{Pt}$ sample for validation was 98.8\%. Lastly, electronic resistances of the support materials were measured by a four-point probe method (RM3-AR, Jandel, UK).

Electrochemical characterization.-To perform electrochemical tests, the bipotentiostat PGSTAT132N (Metrohm Autolab, The Netherlands) controlled by Nova 1.11 software was utilized. Measurements were carried out in $0.1 \mathrm{M} \mathrm{HClO}_{4}(70 \mathrm{wt} \%$, Sigma-Aldrich, USA) as electrolyte at room temperature. A Pt wire presented the counter electrode, whereas the reference electrode was a saturated calomel (SCE, $\mathrm{KCl}$-sat.) or $\mathrm{Hg} / \mathrm{Hg}_{2} \mathrm{SO}_{4}$ electrode. Electrochemical data were converted to the reversible hydrogen electrode (RHE), allowing better comparison with literature. The type of working electrode chosen was dependent on the purpose of study. On the one hand, rotating disk electrodes (RDE) — comprising glassy carbon $(\mathrm{A}=0.2$ $\mathrm{cm}^{2}$ ) with Teflon jacket and fixed inside a rotation system (Pine Research Instrumentation, USA) - were used as working electrode for ORR and ECSA investigation. On the other hand, TEM grids fixed on glassy carbon electrodes by means of a Teflon cap served for identical location TEM. Polishing of working electrodes was carried out $5 \mathrm{~min}$ each with 5.00 and $0.05 \mu \mathrm{m}$ alumina paste (Buehler, USA) and then sonicated in 2-propanol and in water for at least 5 min each.

For RDE measurements, the electrode was coated uniformly with $\mathrm{Pt} / \mathrm{FTO}-\mathrm{rGO}$ or Pt/C material. Therefore, an ink was freshly prepared using $1 \mathrm{mg}$ of catalyst in $0.5 \mathrm{~mL}$ solvent mixture of $165 \mu \mathrm{L} 2$-propanol and $335 \mu \mathrm{L} \mathrm{H}_{2} \mathrm{O} .15 \mu \mathrm{L}$ of $5 \mathrm{wt} \%$ Nafion in 2-propanol was added to the ink before sonication for $1 \mathrm{~h} .14 .7 \mu \mathrm{L}$ of catalyst ink was dropped on the RDE and dried under rotation with $300 \mathrm{rpm}$. In case of the FTO-rGO support, the electrode was coated similarly. RDEs with 
$\mathrm{Pt} / \mathrm{C}$ were prepared in the same way using $1 \mathrm{mg}$ catalyst in $1 \mathrm{~mL}$ solvent mixture with $250 \mu \mathrm{L}$ 2-propanol and $750 \mu \mathrm{L} \mathrm{H}_{2} \mathrm{O}$.

Table I lists the parameters of the electrochemical measuring procedure. First, the catalyst was activated via potential cycling. Next to thermal treatment, ${ }^{38}$ potential cycling results in removal of impurities like residues of ethylene glycol. ${ }^{39,40}$ Then, the catalysts were fully characterized including the analysis of the ECSA and ORR kinetics. Cyclic voltammetry (CV) was performed to get the ECSA from hydrogen underpotential deposition (HUPD). CO stripping voltammetry served for ECSA analysis as well. Carbon monoxide was adsorbed on the catalyst surface by bubbling $\mathrm{CO}$ through the electrolyte for $1 \mathrm{~min}$. After $\mathrm{N}_{2}$ bubbling for another $20 \mathrm{~min}, \mathrm{CV}$ curves between 0.05 and $0.30 \mathrm{~V}_{\mathrm{RHE}}$ ensured complete $\mathrm{CO}$ coverage on platinum. For ORR investigation, rotating disk electrode (RDE) curves were recorded with rotation at 400, 900, 1200, 1600, 2000 and $2500 \mathrm{rpm}$ each to achieve steady state conditions. After characterization, catalysts were aged by use of AST. The technical parameters were summarized in Table I.

For IL-TEM measurements, carbon film coated Au grids (H7, 400 mesh, Plano GmbH, Germany) were used to guarantee sufficient electrical conductance. A drop of catalyst-water-suspension was put on a glass plate. The grid was placed on this droplet to fix the catalyst particles. The catalyst coated TEM grid was then exposed to exactly the same AST described in Table I. To observe catalyst degradation with the microscope the same grid position before and after AST can be investigated.

\section{Results and Discussion}

Transmission electron microscopy with EDS.-TEM images are used to illustrate the progress in Pt/FTO-rGO catalyst production. Figures $1 \mathrm{a}-1 \mathrm{c}$ contrast the microscopic images of reduced graphene oxide, after FTO deposition on rGO and the final Pt catalyst on FTOrGO. Figure 1a shows a wrinkled rGO layer with transparent character. The next TEM image in Figure 1b reveals successful precipitation of FTO nanoparticles on rGO. The evaluation of 300 nanoparticles by the software ImageJ gives an average FTO size of $2.8 \pm 0.9 \mathrm{~nm}$ in diameter. FTO particles occur as aggregates on rGO. In literature, TEM analyses of FTO on reduced graphene oxide ${ }^{30}$ and FTO on multiwalled carbon nanotubes ${ }^{31}$ resulted in similar aggregate observations. Figure 1c depicts FTO-rGO after platinum deposition and shows $\mathrm{Pt}$ dispersion on the substrate with a Pt mass fraction of $21.8 \mathrm{wt} \%$ determined by ICP-MS. The commercial Pt/C catalyst is imaged in Figure 1d illustrating a high $\mathrm{Pt}$ dispersion on the support surface as well and containing $19.1 \mathrm{wt} \%$ platinum according to ICP-MS. Pt nanoparticle size analyses in Figures $1 \mathrm{c}$ and $1 \mathrm{~d}$ reveal the very similar Pt size distribution on FTO-rGO with an average size $\mathrm{x}=1.6 \pm 0.4 \mathrm{~nm}$ and on carbon black with $\mathrm{x}=1.5 \pm 0.4 \mathrm{~nm}$ in diameter. Since Pt distribution and size can have a significant effect on the ECSA and the activity for ORR, ${ }^{41}$ these TEM results point out good preconditions for high comparability of these two catalysts in the following stability investigation.

To get insights into the new Pt/FTO-rGO catalyst in more detail, high resolution TEM with EDS has been carried out. Figure 2
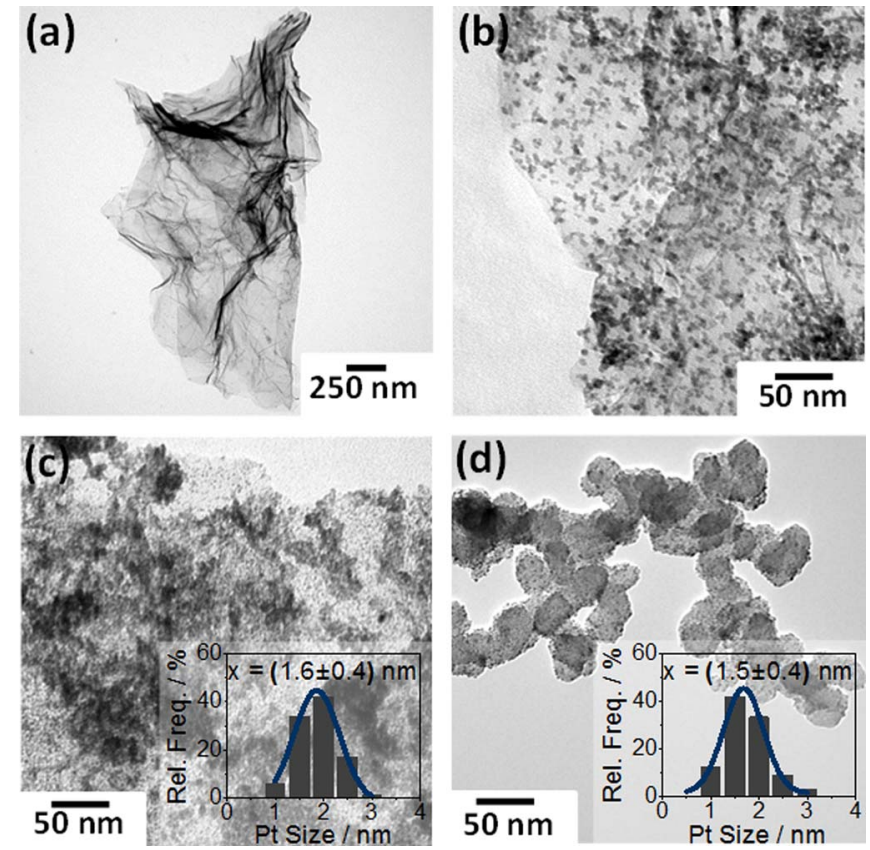

Figure 1. TEM images of rGO (a), FTO particles on rGO (b), Pt/FTO-rGO with averaged $\mathrm{Pt}$ nanoparticle size $\mathrm{x}(\mathrm{c})$ and $\mathrm{Pt} / \mathrm{C}$ with averaged $\mathrm{Pt}$ nanoparticle size $x(d)$.

confirms Pt and also FTO particles attachment on reduced graphene oxide with increasing magnification from left to right. The squares in Figures $2 \mathrm{a}$ and $2 \mathrm{~b}$ show the parts which are magnified in the next image to the right. Identification of Pt and FTO was done by measuring distances in the atomic lattice of the imaged nanocrystals with the software Gwyddion. In Figure 2c, such lattice distances in three different particles are determined and assigned using the inorganic crystal structure database (ICSD). The distance of $0.22 \mathrm{~nm}$ in atomic lattice is assigned to the (111) surface in Pt nanocrystals (ICSD, 00-001-1194), whereas the $0.33 \mathrm{~nm}$ and $0.26 \mathrm{~nm}$ distances correspond to the (110) and (011) surfaces of the cassiterite $\mathrm{SnO}_{2}$ structure in FTO (ICSD, 98-000-9163), respectively.

Furthermore, Figure $2 \mathrm{c}$ reveals $\mathrm{Pt}$ deposition at the interface between FTO and rGO. Kou et al. ${ }^{28}$ reported density functional theory calculations (DFT) with platinum on a nanocomposite of indium tin oxide (ITO) and rGO. They demonstrated the preferred Pt anchoring at ITO-rGO interfaces, which corresponds to our observation of Pt-FTO-rGO interaction in Figure $2 \mathrm{c} .{ }^{28}$ This fact and also the well-known interaction of graphene defect sites with Pt or metal oxide particles ${ }^{15,28,42}$ inspired us to further investigation by EDS mapping, shown in Figure 3. Both elements - platinum in red and tin in green - have been detected on the rGO surface, evidencing the nanoparticle anchoring on rGO. In case of $\mathrm{Sn}$ some aggregates of
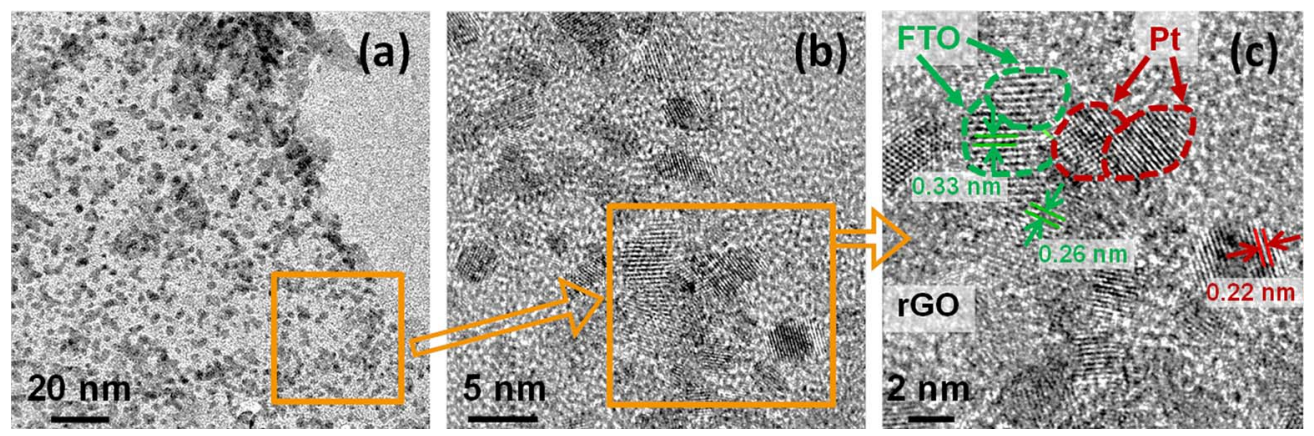

Figure 2. HR-TEM images of Pt and FTO nanoparticles on rGO. 


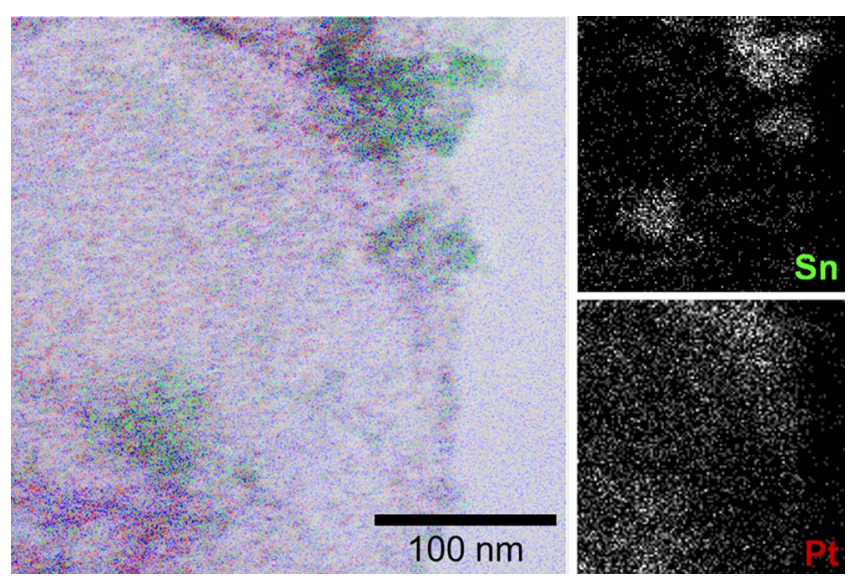

Figure 3. EDS mapping of Pt/FTO-rGO sample with detection of Sn (green), $\mathrm{Pt}$ (red) and C (blue).

FTO particles can be seen. However, platinum is highly dispersed on rGO and on FTO, whereas the EDS mapping displays the preferred Pt deposition on FTO. Hence, EDS additionally evidences interaction between Pt, FTO and rGO and the formation of Pt-FTO-rGO interfaces.

$\boldsymbol{X R D}$ and $\boldsymbol{X P S}$. - Further investigation was carried out by X-ray powder diffraction in Figure 4, while the diffractograms are compared with references from the ICS database. First, the crystalline structure of the FTO-rGO nanocomposite is determined. XRD shows the crystalline FTO structure which is similar to cassiterite tin (IV) oxide. The (110) and (011) surfaces at about $27^{\circ}$ and $34^{\circ}$ lead to the highest signal intensities and have also been visible under the microscope in Figure 2c. The crystallite size L of FTO particles on rGO is calculated using Scherrer's Equation 1 consisting of X-ray reflection angle $\theta$, wavelength of $\mathrm{Cu} \mathrm{K} \alpha$ radiation $\lambda$, form factor $\mathrm{K}$ of 0.89 and the fully peak width at half maximum FWHM. The three reflections with highest intensity of the surfaces (110), (011) and (121) are used to obtain the crystallite size and XRD of natural graphite from rGO synthesis serves for correcting FWHM values. The FTO particles on rGO exhibit a crystallite size of $5.1 \pm 0.4 \mathrm{~nm}$. TEM imaged smaller particles in Figures 1 and 2 and gave a FTO particle size of $2.8 \pm 0.9 \mathrm{~nm}$. TEM is limited to $2 \mathrm{D}$ imaging and the degree of contrast of the materials, whereas Scherrer's equation contains assumptions like the form factor $\mathrm{K}$. Because of these uncertainties in size determination, both methods have been considered here to study FTO-rGO. Furthermore, the expected (002) reflection at about $27^{\circ}$ assigned to reduced graphene oxide $^{43}$ cannot be observed in Figure 4 due to low intensity and an

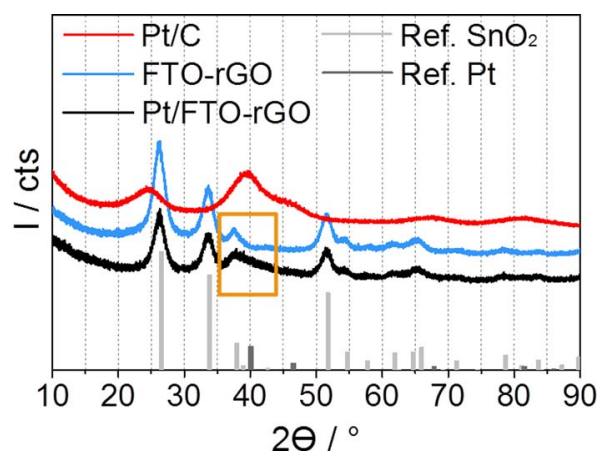

Figure 4. X-ray powder diffraction of the FTO-rGO nanocomposite and of $\mathrm{Pt} / \mathrm{FTO}-\mathrm{rGO}$ and Pt/C catalysts. References from ICS database included.

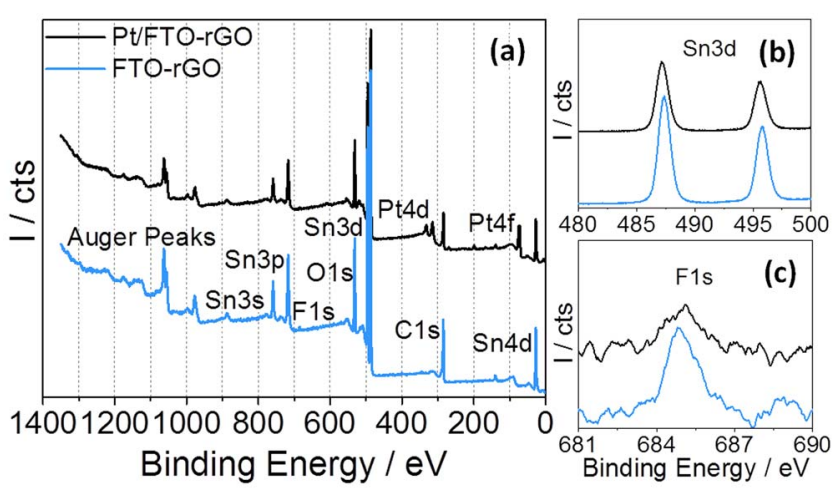

Figure 5. XP spectra of the FTO-rGO nanocomposite and of Pt/FTO-rGO with survey scan (a), high resolution scan of Sn3d (b) and F1s (c).

overlap with (110) $\mathrm{SnO}_{2}$.

$$
\mathrm{L}=\frac{\mathrm{K} \cdot \lambda}{\mathrm{FWHM} \cdot \cos (\theta)}
$$

Second, Figure 4 contains the XRD pattern of the catalysts $\mathrm{Pt} / \mathrm{FTO}-\mathrm{rGO}$ and $\mathrm{Pt} / \mathrm{C}$. Pt particles in nanometer range determined via TEM analysis result in broad reflections with low intensity. In case of $\mathrm{Pt} / \mathrm{C}$, we see next to the carbon signal at about $27^{\circ}$ the appropriate Pt reflections. For Pt/FTO-rGO it is more difficult to see platinum due to the overlapping FTO reflections. Only the framed area in Figure 4 indicates the presence of platinum on FTO-rGO via $\mathrm{XRD}$. The FTO reflection about $38^{\circ}$ shows a distinct right shoulder in case of Pt/FTO-rGO which is traced back to Pt (111) surface.

To investigate the fluorine-doping of $\mathrm{SnO}_{2}$, X-ray photoelectron spectra have been recorded. Figure 5 shows the XPS results and compares the results for FTO-rGO without and with deposited Pt nanoparticles. The survey scans in Figure 5a exhibit the same peaks, except the Pt related signals in case of FTO-rGO. The Sn3d peaks are plotted in Figure $5 b$ and the F1s signal in Figure $5 c$. The $S n 3 d_{5 / 2}$ peak has a binding energy between $487.0-487.5 \mathrm{eV}$ and $\mathrm{Sn} 3 \mathrm{~d}_{3 / 2}$ has a binding energy between $495.5-496.0 \mathrm{eV}$ assigning to a tetravalentoxidation state. ${ }^{44}$ Metallic tin or $\mathrm{SnO}$ signals would appear at lower $\mathrm{Sn} 3 \mathrm{~d}_{5 / 2}$ binding energies around $485 \mathrm{eV}$ and $486 \mathrm{eV}$, respectively. $\mathrm{Sn} 3 \mathrm{~d}$ is then used to determine the content of fluorine in FTO particles. Figure $5 \mathrm{c}$ shows the F1s peak with low intensity due to small degree of fluorine-doping. In synthesis, we used a molar ratio of $\mathrm{NH}_{4} \mathrm{~F} / \mathrm{Sn}=$ 2 and achieved a F-doping of 8 at\% in case of FTO-rGO spectrum and 9 at $\%$ for Pt/FTO-rGO spectrum.

ECSA and ORR.-After physical characterization of the catalysts, the electrochemical properties with respect to PEM fuel cell application are studied. Cyclic and CO stripping voltammetry curves in Figure 6 allow ECSA determination of platinum. The first established method is the hydrogen underpotential deposition (HUPD) and takes into account the oxidation charge from previously adsorbed hydrogen on platinum between around 0.0 and $0.4 \mathrm{~V}_{\mathrm{RHE}}$. $^{5,45,46}$ The other method uses the adsorption and subsequent oxidation of carbon monoxide on $\mathrm{Pt}$ in a higher potential range between approximately 0.4 and $1.0 \mathrm{~V}_{\mathrm{RHE}}{ }^{47-49}$ Equation 2 takes the oxidation charge $\mathrm{Q}_{\mathrm{Pt}}$ of hydrogen or $\mathrm{CO}$ divided by the scan rate $\nu$, the charge density $\rho$ (hydrogen with $2.1 \mathrm{C} \mathrm{m}_{\mathrm{Pt}^{-2}}{ }^{-2}$ or $\mathrm{CO}$ with $4.2 \mathrm{C} \mathrm{m}_{\mathrm{Pt}}{ }^{-2}$ ) and the Pt loading $\mathrm{L}_{\mathrm{Pt}}$ on the electrode surface. ECSA values have been calculated using real Pt loadings determined through ICP mass spectrometry and are depicted in Table II.

$$
\mathrm{ECSA}=\frac{\mathrm{Q}_{\mathrm{Pt}}}{\vartheta \cdot \rho \cdot \mathrm{L}_{\mathrm{Pt}}}
$$

Figures $6 \mathrm{a}$ and $6 \mathrm{~b}$ show the voltammetry results of new Pt/FTOrGO catalyst and standard Pt/C, respectively. In Figure 6a, voltammetry curves have also been recorded for FTO-rGO support without 

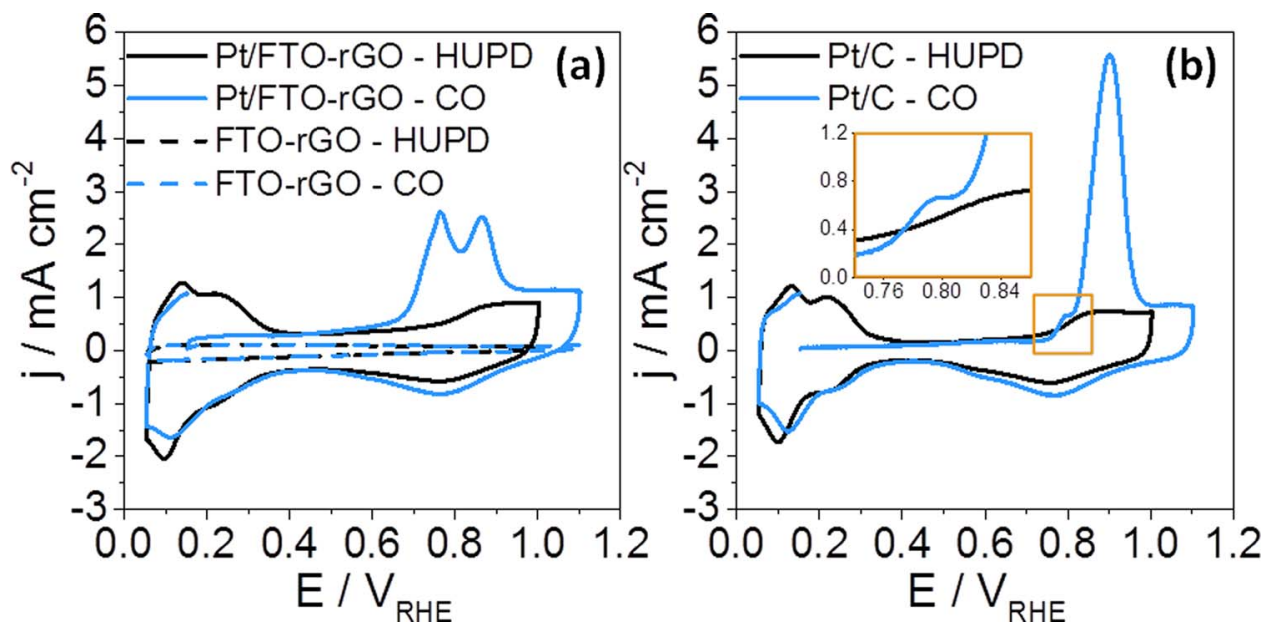

Figure 6. Cyclic voltammetry curves and CO stripping voltammograms of Pt/FTO-rGO catalyst and FTO-rGO support (a) and Pt/C (b).

platinum highlighting the solely adsorption and catalytic oxidation of hydrogen and carbon monoxide on Pt. Thus, the nanocomposite of FTO particles and reduced graphene oxide exhibits no electrochemical surface. CO stripping voltammetry on Pt/FTO-rGO results in two overlapping peaks with similar intensities at 0.76 and $0.86 \mathrm{~V}_{\mathrm{RHE}}$, respectively. This indicates varying $\mathrm{CO}$ binding strength on Pt and can be caused by $\mathrm{CO}$ chemisorption on different Pt surface sites ${ }^{50,51}$ on the one hand or effects of the support on interactions between $\mathrm{Pt}$ and $\mathrm{CO}$ on the other hand. ${ }^{52}$ Ruiz Camacho et al. ${ }^{52}$ tested platinum on different metal oxide-carbon composites by $\mathrm{CO}$ stripping voltammetry combined with in situ infrared reflection absorption spectroscopy (FTIRS). They interpreted increased stretching frequencies of $\mathrm{CO}$ molecules adsorbed on $\mathrm{Pt} / \mathrm{SnO}_{2}-\mathrm{C}$ in contrast to $\mathrm{Pt} / \mathrm{C}$ by lower $\mathrm{CO}$ adsorption energies. Electronic influences of metal oxides on $\mathrm{Pt}$ result into reduced electron donation from platinum to $\mathrm{CO}$. Owing to these complex CO-Pt-oxide interactions, they observed a negative $\mathrm{CO}$ peak shift in voltammetry experiments as consequence of $\mathrm{CO}$ binding weakening on Pt. We suggest that the detection of two $\mathrm{CO}$ signals for Pt/FTO-rGO in Figure 6a arise from Pt particles interacting with FTO (CO signal at $\left.0.76 \mathrm{~V}_{\mathrm{RHE}}\right)$ and Pt particles not interacting with FTO (CO signal at $0.86 \mathrm{~V}_{\mathrm{RHE}}$ ). TEM measurements in Figures 2 and 3 showed Pt deposition on different surfaces and support our assumption at this point.

Figure 6b displays cyclic and $\mathrm{CO}$ stripping voltammetry for commercial $\mathrm{Pt} / \mathrm{C}$. The oxidation and desorption of $\mathrm{CO}$ lead to a signal around $0.90 \mathrm{~V}_{\mathrm{RHE}}$ with a shoulder on the low potential flank. In our previous study, ${ }^{53} \mathrm{CO}$ stripping curves have been measured for selfprepared $\mathrm{Pt} / \mathrm{C}$ and $\mathrm{Pt}$ on rGO only by use of the same electrochemical setup and procedure. Both materials - $\mathrm{Pt} / \mathrm{C}$ and $\mathrm{Pt} / \mathrm{rGO}-$ showed a similar signal centered at $0.88 \mathrm{~V}_{\mathrm{RHE}}$ with left shoulder compared to the $\mathrm{CO}$ stripping curve of commercial $\mathrm{Pt} / \mathrm{C}$ in this study. Coming back to the CO stripping experiment on the Pt/FTO-rGO, the comparison to $\mathrm{Pt} / \mathrm{C}$ supports our assignment of the right $\mathrm{CO}$ peak observed around $0.86 \mathrm{~V}_{\mathrm{RHE}}$ in Figure $6 \mathrm{a}$ to Pt particles on FTO-rGO substrate interacting solely with carbon substrate because of very similar peak positions. Thus, the other $\mathrm{CO}$ peak at $0.76 \mathrm{~V}_{\mathrm{RHE}}$ is suggested to $\mathrm{Pt}$ particles on FTO-rGO substrate interacting with FTO. However, since $\mathrm{CO}$ stripping on $\mathrm{Pt} / \mathrm{C}$ shows a shoulder also in a lower potential range due to $\mathrm{CO}$ interaction with different Pt surfaces, we have to keep in mind the same Pt surface site effects in case of Pt/FTO-rGO at lower potentials around $0.76 \mathrm{~V}_{\mathrm{RHE}}$. $\mathrm{CO}$ oxidation on polycrystalline platinum e.g. occurs at higher potentials than $\mathrm{CO}$ stripping on $\mathrm{Pt}$ (111) surface. ${ }^{51,54}$

Performing HUPD, ECSAs are $53 \mathrm{~m}^{2} \mathrm{~g}_{\mathrm{Pt}}{ }^{-1}$ for Pt/FTO-rGO and $65 \mathrm{~m}^{2} \mathrm{~g}_{\mathrm{Pt}}{ }^{-1}$ for $\mathrm{Pt} / \mathrm{C}$. Pt distribution on the substrate and the $\mathrm{Pt}$ particle size are influence factors on the electrochemical surface of catalysts. ${ }^{41}$ TEM analysis in Figure 1 revealed comparable Pt particle sizes on FTO-rGO and C. However, the Pt distribution on FTO-rGO in Figure 3 showed a preferred interaction with FTO aggregates, which can have the effect of lowered electrochemical surface area in case of Pt/FTO-rGO. Determination with the aid of CO stripping voltammetry gives $38 \mathrm{~m}^{2} \mathrm{~g}_{\mathrm{Pt}^{-1}}{ }^{-1}$ and $73 \mathrm{~m}^{2} \mathrm{~g}_{\mathrm{Pt}}{ }^{-1}$ in case of Pt/FTO-rGO and $\mathrm{Pt} / \mathrm{C}$, confirming the tendency of higher ECSA for $\mathrm{Pt} / \mathrm{C}$ compared to Pt/FTO-rGO. However, deviation between ECSA methods is $29 \%$ for Pt/FTO-rGO and thus three times higher than for Pt/C. We believe in the ECSA $A_{\text {HUPD }}$ of $53 \mathrm{~m}^{2} \mathrm{~g}_{\mathrm{Pt}}{ }^{-1}$ for Pt/FTO-rGO, because the observed lower $\mathrm{CO}$ binding strength on $\mathrm{Pt} / \mathrm{FTO}-\mathrm{rGO}$ catalyst in Figure 6a suggests higher $\mathrm{CO}$ tolerance due to the use of metal oxide support. ${ }^{52,55}$ Similar deviation between the methods of HUPD and CO has been observed for Pt/ITO-rGO ${ }^{53}$ and PtSn alloy on carbon black with $\mathrm{SnO}_{2}{ }^{56}$

Investigations of the oxygen reduction reaction have been carried out. ORR polarization curves at different electrode rotation rates for new Pt/FTO-rGO catalyst and for the FTO-rGO nanocomposite only are compared in Figure 7a. Because the nanocomposite without platinum shows no activity for the reduction reaction of $\mathrm{O}_{2}$, ORR study of the support material was restricted to rotation at $1600 \mathrm{rpm}$. However, the Pt/FTO-rGO catalyst shows ORR activity and has been measured at different rotation speeds. Generally, at high potentials above $0.9 \mathrm{~V}_{\mathrm{RHE}}$, the diffusion limitation is negligible and the ORR kinetics become predominant. At potentials below approximately $0.85 \mathrm{~V}_{\mathrm{RHE}}$, we see a strong dependence of the current densities on the rotation rate. Based on this dependency, Koutecky-Levich (K-L) relation allows the verification of transferred electrons in $\mathrm{O}_{2}$ reduction and is described in Equation 3, where $\mathrm{j}$ is the measured current density, $\mathrm{j}_{\mathrm{kin}}$ the kinetic and $\mathrm{j}_{\mathrm{lim}}$ the diffusion-limited current density, respectively. $\mathrm{n}$ is the

Table II. ECSAs before and after AST.

Before AST

\begin{tabular}{lcc} 
& $\mathrm{ECSA}_{\mathrm{HUPD}} / \mathrm{m}^{2} \mathrm{~g}_{\mathrm{Pt}}{ }^{-1}$ & $\mathrm{ECSA}_{\mathrm{CO}} / \mathrm{m}^{2} \mathrm{~g}_{\mathrm{Pt}}{ }^{-1}$ \\
\hline $\mathrm{Pt} / \mathrm{FTO}-\mathrm{rGO}$ & 53 & 38 \\
$\mathrm{Pt} / \mathrm{C}$ & 65 & 73
\end{tabular}

\begin{tabular}{cc}
\hline $\mathrm{ECSA}_{\mathrm{HUPD}} / \mathrm{m}^{2} \mathrm{~g}_{\mathrm{Pt}}{ }^{-1}$ & $\mathrm{ECSA}_{\mathrm{CO}} / \mathrm{m}^{2} \mathrm{~g}_{\mathrm{Pt}}{ }^{-1}$ \\
40 & 26 \\
48 & 48
\end{tabular}

After AST

Change of 

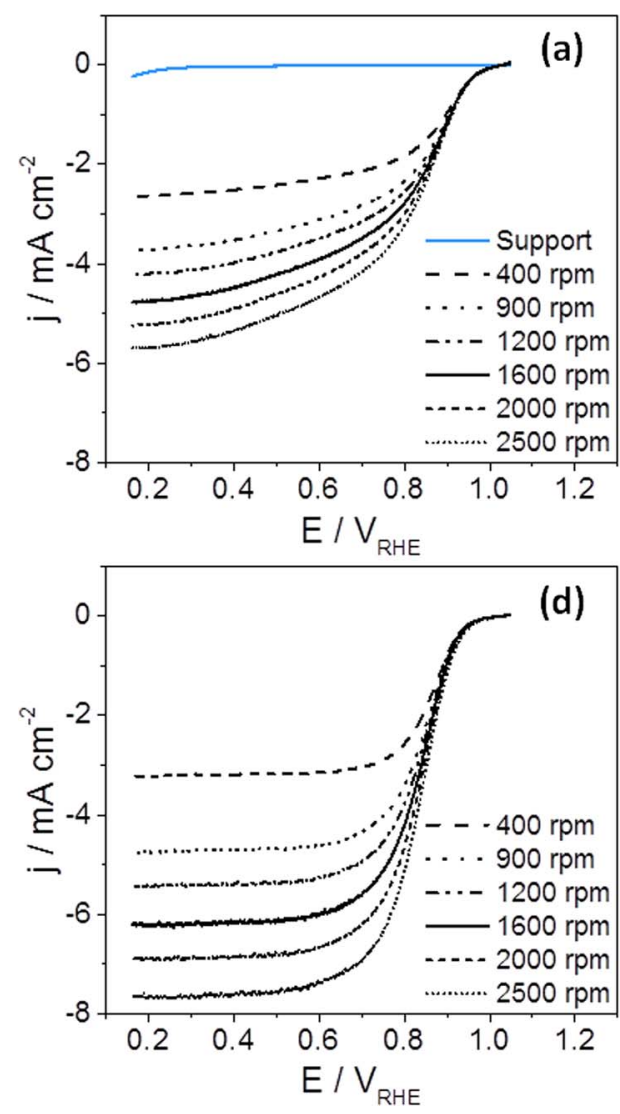

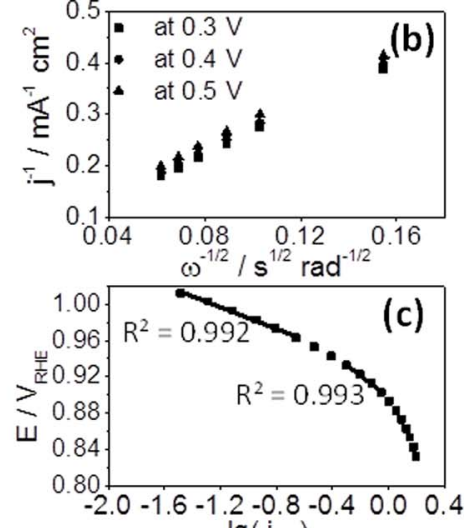

$\lg \left(\mathrm{j}_{\mathrm{kin}}\right)$

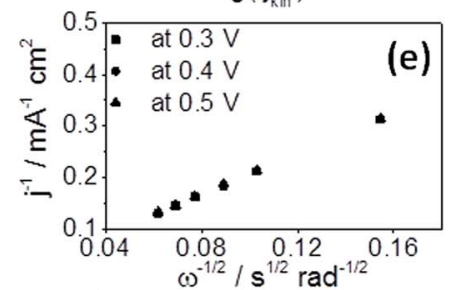

$\omega^{-1 / 2} / \mathrm{s}^{1 / 2} \mathrm{rad}^{-1 / 2}$

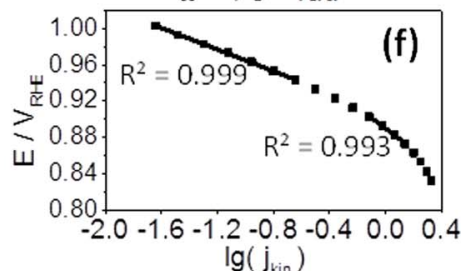

Figure 7. ORR data in $\mathrm{O}_{2}$-saturated $0.1 \mathrm{M} \mathrm{HClO}_{4}$ solution. Cathodic scans of $\mathrm{Pt} / \mathrm{FTO}-\mathrm{rGO}$ at different rotation speeds and FTO-rGO at $1600 \mathrm{rpm}$ (a) and of Pt/C (d), K-L plots of Pt/FTO-rGO (b) and Pt/C (e), Tafel plots from ORR at $1600 \mathrm{rpm}$ for Pt/FTO-rGO (c) and Pt/C (f). number of transferred electrons per oxygen molecule, $\mathrm{F}$ the Faraday constant $\left(96,485 \mathrm{C} \mathrm{mol}^{-1}\right), v$ the kinematic viscosity of the electrolyte $\left(0.01 \mathrm{~cm}^{2} \mathrm{~s}^{-1}\right),{ }^{17} \mathrm{D}$ the diffusion coefficient of $\mathrm{O}_{2}\left(1.93 \times 10^{-5} \mathrm{~cm}^{2}\right.$ $\left.\mathrm{s}^{-1}\right),{ }^{17} \mathrm{c}^{*}$ the $\mathrm{O}_{2}$ concentration in solution $\left(1.26 \times 10^{-3} \mathrm{~mol} \mathrm{~L}^{-1}\right)^{17}$ and $\omega$ is the rotation rate.

$$
\frac{1}{\mathrm{j}}=\frac{1}{\mathrm{j}_{\mathrm{kin}}}+\frac{1}{\mathrm{j}_{\mathrm{lim}}}=\frac{1}{0.62 \cdot \mathrm{n} \cdot \mathrm{F} \cdot \vartheta^{-1 / 6} \cdot \mathrm{D}^{2 / 3} \cdot \mathrm{c}^{*}} \cdot \omega^{-1 / 2}
$$

Based on this K-L relation, a diffusion-limited current density of $5.8 \mathrm{~mA} \mathrm{~cm} \mathrm{~cm}^{-2}$ is expected at a rotation speed of $1600 \mathrm{rpm} .{ }^{49}$ With regard to $\mathrm{Pt} / \mathrm{FTO}-\mathrm{rGO}$ in Figure $7 \mathrm{a}$ lower $\mathrm{j}_{\text {lim }}$ values than expected are recorded, whereas next to catalyst distribution on the electrode the catalyst itself can cause such deviations. ${ }^{57}$ Differing morphology and particle size of FTO-rGO substrate compared to Vulcan XC72 in Figure 1 and the electrical resistance may have an influence on diffusion-limited current density. Here, the electrical conductivity of the support films has additionally been determined using the fourpoint probe method and was found to be in order of $\mathrm{C}\left(106 \mathrm{~S} \mathrm{~cm}^{-1}\right)$ $>$ rGO $\left(65 \mathrm{~S} \mathrm{~cm}^{-1}\right)>$ FTO-rGO $\left(55 \mathrm{~S} \mathrm{~cm}^{-1}\right)$. Furthermore, comparably lowered diffusion-limited ORR currents are reported in case of $\mathrm{Pt} / \mathrm{Sb}-\mathrm{SnO}_{2}$ and $\mathrm{Pt} / \mathrm{Ru}-\mathrm{SnO}_{2},{ }^{58} \mathrm{Pt}$ on Sb-doped $\mathrm{SnO}_{2}{ }^{59}$ and $\mathrm{Pt} / \mathrm{TiO}_{2}-$ C. ${ }^{60}$ These materials have similarity to $\mathrm{Pt} / \mathrm{FTO}-\mathrm{rGO}$ presented here. $\mathrm{K}-\mathrm{L}$ plots resulting from Equation 3 in Figure $7 \mathrm{~b}$ for $\mathrm{Pt} / \mathrm{FTO}-\mathrm{rGO}$ and in Figure 7e for Pt/C illustrate the correlation between $\mathrm{j}_{\mathrm{lim}}$ and the rotation speed at potentials from 0.3 to $0.5 \mathrm{~V}_{\mathrm{RHE}}$. The number of transferred electrons per $\mathrm{O}_{2}$ molecule during ORR is 3.8 in case of $\mathrm{Pt} / \mathrm{FTO}-\mathrm{rGO}$ and 4.4 in case of $\mathrm{Pt} / \mathrm{C}$. This is an indication of a four-electron reaction pathway, going along with the well-studied $4 \mathrm{e}^{-}$ pathway in case of Pt catalysts. ${ }^{61,62}$

ORR data are further used to generate Tafel plots in Figure $7 \mathrm{c}$ for $\mathrm{Pt} / \mathrm{FTO}-\mathrm{rGO}$ and Figure $7 \mathrm{f}$ for $\mathrm{Pt} / \mathrm{C}$ by Koutecky-Levich and Butler-Volmer relations. ${ }^{49,63,64}$ In general, two regions with characteristic Tafel slopes are ascribed to oxygen reduction on platinum catalysts. The low current region around $0.95-1.00 \mathrm{~V}_{\mathrm{RHE}}$ usually gives $\mathrm{m}_{\mathrm{I}}=-60 \mathrm{mV} \mathrm{dec}{ }^{-1}$, whereas the higher current range around 0.90 and $0.95 \mathrm{~V}_{\mathrm{RHE}}$ usually gives $\mathrm{m}_{\mathrm{II}}=-120 \mathrm{mV} \mathrm{dec}{ }^{-1}{ }^{65}$ Linear fitting has been carried out in both regions with correlation coefficients higher than 0.99 for both catalysts. The calculated Tafel slopes for $\mathrm{Pt} / \mathrm{FTO}-\mathrm{rGO}$ are $\mathrm{m}_{\mathrm{I}}=-60 \mathrm{mV} \mathrm{dec}{ }^{-1}$ and $\mathrm{m}_{\mathrm{II}}=-121 \mathrm{mV} \mathrm{dec}^{-1}$, and the slopes for Pt/C are $\mathrm{m}_{\mathrm{I}}=-60 \mathrm{mV} \mathrm{dec}{ }^{-1}$ and $\mathrm{m}_{\mathrm{II}}=-115 \mathrm{mV}$ $\mathrm{dec}^{-1}$, complying with the expected values for ORR on platinum catalysts.

Last, RDE experiments serve for determination of the catalytic ORR activity listed in Table III. The kinetic current at $0.9 \mathrm{~V}_{\mathrm{RHE}}$ and $1600 \mathrm{rpm}$ of the cathodic sweep is calculated by the K-L equation and normalized to the electroactive Pt area from HUPD in

Table III. Activities for ORR before and after AST.

Before AST

\begin{tabular}{cc}
\hline $\begin{array}{c}\text { Specific } \\
\text { Activity/mA cm }\end{array}$ & $\begin{array}{c}\text { Mass } \\
\text { Activity/A } \mathrm{gPt}^{-1}\end{array}$ \\
\hline 0.095 & 49.9 \\
0.059 & 38.3
\end{tabular}

After AST

\begin{tabular}{ccccc}
\hline $\begin{array}{c}\text { Specific } \\
\text { Activity/mA cm }\end{array}$ & $\begin{array}{c}\text { Mass } \\
\text { Activity/A } \text { g }^{-2}\end{array}$ & & $\begin{array}{c}\text { Specific } \\
\text { Activity/\% }\end{array}$ & $\begin{array}{c}\text { Mass } \\
\text { Activity/\% }\end{array}$ \\
\hline 0.054 & 21.4 & 43 & 57 \\
0.030 & 14.3 & 49 & 63
\end{tabular}



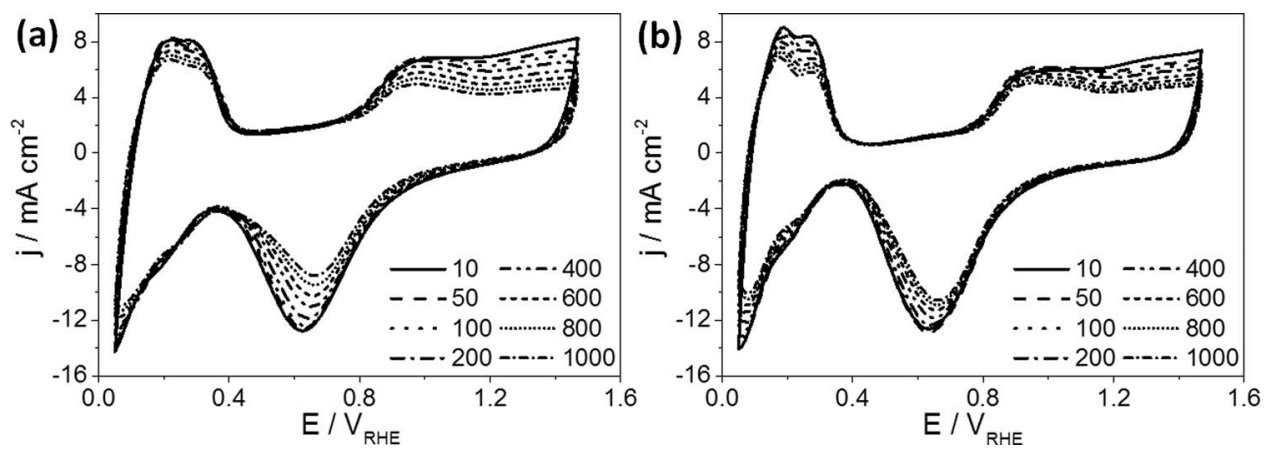

Figure 8. $\mathrm{CV}$ curves over time of stability testing (0.05-1.47 $\mathrm{V}_{\mathrm{RHE}}, 500 \mathrm{mV} \mathrm{s}{ }^{-1}, \mathrm{O}_{2}$-saturated $0.1 \mathrm{M} \mathrm{HClO}_{4}$ solution) for Pt/FTO-rGO (a) and Pt/C (b).

Figure 6 a (specific activity) or normalized to the mass of platinum (mass activity) which was calculated via ICP-MS. Commercial Pt/C exhibits a specific activity of $0.059 \mathrm{~mA} \mathrm{~cm} \mathrm{~cm}^{-2}$ and a mass activity of $38.3 \mathrm{~A} \mathrm{~g} \mathrm{gt}^{-1}$. The comparison to $\mathrm{Pt} / \mathrm{C}$ catalysts in literature is limited. First, size and surface morphology of Pt are reported to have an influence on catalytic ORR activity with a maximized mass activity for particle sizes of around 3-5 nm. ${ }^{66-68}$ Second, the experimental RDE conditions affect the activity as reviewed by Kocha et al ${ }^{69}$ Next to the impact of electrolyte, ${ }^{70}$ cyclic voltammetry provides different currents for kinetic calculation. Since the cathodic sweep, evaluated here for considering the lower limit of activity, starts in the Pt-oxide range, specific and mass activities are lower than calculated from anodic sweep. Literature examples of $20 \mathrm{wt} \% \mathrm{Pt} / \mathrm{C}$ after evaluation of cathodic scans are $0.016 \mathrm{~mA} \mathrm{~cm}{ }^{-2} / 10.0 \mathrm{~A} \mathrm{~g}_{\mathrm{Pt}}{ }^{-1}, 71$ and $0.020 \mathrm{~mA}$ $\mathrm{cm}^{-2} / 10.6 \mathrm{~A} \mathrm{~g} \mathrm{gt}_{\mathrm{Pt}}{ }^{-1} .{ }^{72}$ Further ORR activities of $20 \mathrm{wt} \% \mathrm{Pt} / \mathrm{C}$ are around $0.085 \mathrm{~mA} \mathrm{~cm}{ }^{-2} / 56.0 \mathrm{~A} \mathrm{~g}_{\mathrm{Pt}}{ }^{-1},{ }^{73}$ and $0.291 \mathrm{~mA} \mathrm{~cm}{ }^{-2} / 150 \mathrm{~A}$ $\mathrm{g}_{\mathrm{Pt}}{ }^{-1}$ using anodic scan evaluation. ${ }^{74} \mathrm{ORR}$ activity of commercial $\mathrm{Pt} / \mathrm{C}$ found in this study is in agreement with literature values for similar $\mathrm{Pt} / \mathrm{C}$. In this work, both catalysts, $\mathrm{Pt} / \mathrm{C}$ and Pt/FTO-rGO, are highly comparable with respect to their similar Pt particle size in Figure 1 as well as to RDE conditions in Table I ensuring ORR comparability.

For Pt/FTO-rGO the specific activity is $0.095 \mathrm{~mA} \mathrm{~cm}^{-2}$ and the mass activity is $49.9 \mathrm{~A} \mathrm{~g}_{\mathrm{Pt}}{ }^{-1}$, which is $35 \%$ and $23 \%$ higher than the activity of $\mathrm{Pt} / \mathrm{C}$, respectively. Although the physical characterization of both catalysts showed comparable Pt sizes, shape and crystallinity, the ORR activities are different. Kinumoto et al. ${ }^{75}$ investigated $\mathrm{Pt}$ on supports with different $\mathrm{SnO}_{2}$ /carbon black ratios. The catalyst with highest tin oxide proportion showed the highest ORR activity despite comparable Pt particles. This suggests the dependency of ORR activity on $\mathrm{Pt}$-support interactions.

Accelerated stress test.-Next to catalytic activity, the stability of potential FC catalysts is an important issue. Thus, the catalyst $\mathrm{Pt} / \mathrm{FTO}-\mathrm{rGO}$ was exposed to an accelerated stress test which consists of 1000 potential cycles between 0.05 and $1.47 \mathrm{~V}_{\mathrm{RHE}}$ in $\mathrm{O}_{2}$-saturated solution and was compared to commercial Pt/C. Figure 8 shows selected cycles during the stress test for Pt/FTO-rGO in Figure 8a and $\mathrm{Pt} / \mathrm{C}$ in Figure $8 \mathrm{~b}$. The signals assigned to platinum reactions (hydrogen range approx. 0.0-0.4 $\mathrm{V}_{\mathrm{RHE}}$ and oxygen range above 0.4 $\mathrm{V}_{\mathrm{RHE}}$ ) decrease with time of stability testing in both graphs indicating degradation of both catalysts. The decrease in hydrogen reactions on platinum surface seems to be higher for commercial $\mathrm{Pt} / \mathrm{C}$ in Figure $8 \mathrm{~b}$, while the oxygen reactions seem to underlie higher changes for Pt/FTO-rGO in Figure 8a. In the next paragraphs, a further analysis of Pt degradation as well as support degradation is carried out in more detail.

Figure 9 deals with catalyst properties before and after AST, whereas cyclic and CO stripping voltammetry curves before and after stability testing are contrasted in Figures 9a-9d. The CV curves show that the intensities of Pt related signals in the hydrogen (approximately $0.0-0.4 \mathrm{~V}_{\mathrm{RHE}}$ ) as well as in the oxygen range (above $0.4 \mathrm{~V}_{\mathrm{RHE}}$ ) are decreased after the test. With respect to the stripping voltammetry, we observe decreased peak intensities as well, but significant differences in $\mathrm{CO}$ chemisorption occurred after AST. While $\mathrm{CO}$ sorption on $\mathrm{Pt} / \mathrm{C}$ only undergoes an intensity decrease, the $\mathrm{CO}$ oxidation peak in case of Pt/FTO-rGO changed dramatically after the stress test. The signal centered at $0.86 \mathrm{~V}_{\mathrm{RHE}}$ is almost disappeared. Instead, the $\mathrm{CO}$ oxidation peak on $\mathrm{Pt}$ is shifted to lower potentials. Although the peak at $0.76 \mathrm{~V}_{\mathrm{RHE}}$ occurring before the stability testing is still present after the test, this signal is significantly narrower and shows a distinct shoulder on the low potential flank now. Furthermore, a very broad signal starting at approximately $0.4 \mathrm{~V}_{\mathrm{RHE}}$ is arisen due to potential cycling. Potential shift of $\mathrm{CO}$ desorption and oxidation to lower values after the stability test implies weakened $\mathrm{CO}$ binding on Pt caused by changes of the Pt particles regarding size and crystallinity. ${ }^{76}$ For example, platinum dissolution and agglomeration are well-known degradation paths leading to such effects. They are studied using IL-TEM in this work; the results are shown below in Figure 11 and will be discussed there. ${ }^{4}$ These indications of catalyst degradation become apparent by calculating the electroactive Pt surface. Table II compares the ECSA losses for both catalysts. With respect to Pt/FTO-rGO, ECSA $\mathrm{HUPD}_{\mathrm{H}}$ decreased by $24 \%$ and ECSA $\mathrm{CO}_{\mathrm{CO}}$ decreased by $30 \%$. Regarding the commercial Pt/C, ECSA decreased by $27 \%$ using HUPD and by $34 \%$ using of $\mathrm{CO}$ sorption. Thus, both methods result into slightly stronger ECSA decrease of commercial Pt/C compared to Pt/FTO-rGO.

Figures $9 \mathrm{e}-9 \mathrm{f}$ compare the ORR polarization curves and the related Tafel plots before and after exposure to potential cycling. In the higher potential range around $0.9 \mathrm{~V}_{\mathrm{RHE}}$, we observe a shift for both catalysts to lower potentials and thus higher overpotentials for ORR. This negative shift caused by catalyst degradation is also visible in the Tafel plots. In the potential range below $0.6 \mathrm{~V}_{\mathrm{RHE}}, \mathrm{Pt} / \mathrm{FTO}-\mathrm{rGO}$ in Figure 9e shows a current plateau being slightly shifted to higher reductive current densities after stability testing, whereas the diffusionlimited current density of $\mathrm{Pt} / \mathrm{C}$ in Figure $9 \mathrm{f}$ remains unchanged. On the one hand, the coating of catalyst material on the electrode plays a role in the diffusion-limited range and on the other hand properties of the catalyst itself may have an influence on $\mathrm{j}_{\text {lim }} \cdot{ }^{49,71}$ Possible changes of these factors during AST would lead to an influence on $j_{\text {lim }}$ in ORR investigation of Pt/FTO-rGO. Losses in ORR activity are illustrated in Table III. In terms of figures, the specific ORR activity of Pt/FTOrGO decreased by $43 \%$ and of commercial Pt/C by $49 \%$, whereas the mass activities decreased by $57 \%$ and $63 \%$, respectively. Although the specific activity relativizes differences in ECSA loss between the two catalysts, the decrease in mass as well as specific catalytic activity for oxygen reduction is slightly larger in case of $\mathrm{Pt} / \mathrm{C}$.

Degradation of the supports is electrochemically studied by two parameters, the double layer capacitance $\mathrm{c}_{\mathrm{DL}}$ and the formation of hydroquinone/quinone functionalities as partially oxidized carbon due to corrosion. To determine the double layer capacitance with prevention of faradaic interferences, hydrogen reactions on $\mathrm{Pt}$ were suppressed via CO adsorption, as suggested in literature. ${ }^{48,49}$ Then, cyclic voltammetry is conducted between 0.05 and $0.30 \mathrm{~V}_{\mathrm{RHE}}$. To assess the extent of carbon corrosion, oxidation of hydroquinone to quinone is detected around $0.6 \mathrm{~V}_{\mathrm{RHE}}$ during $\mathrm{CV}$ experiments. The released charge $\mathrm{Q}_{\mathrm{HQ} / \mathrm{Q}}$ is proportional to the amount of hydroquinone species on the rGO surface. 

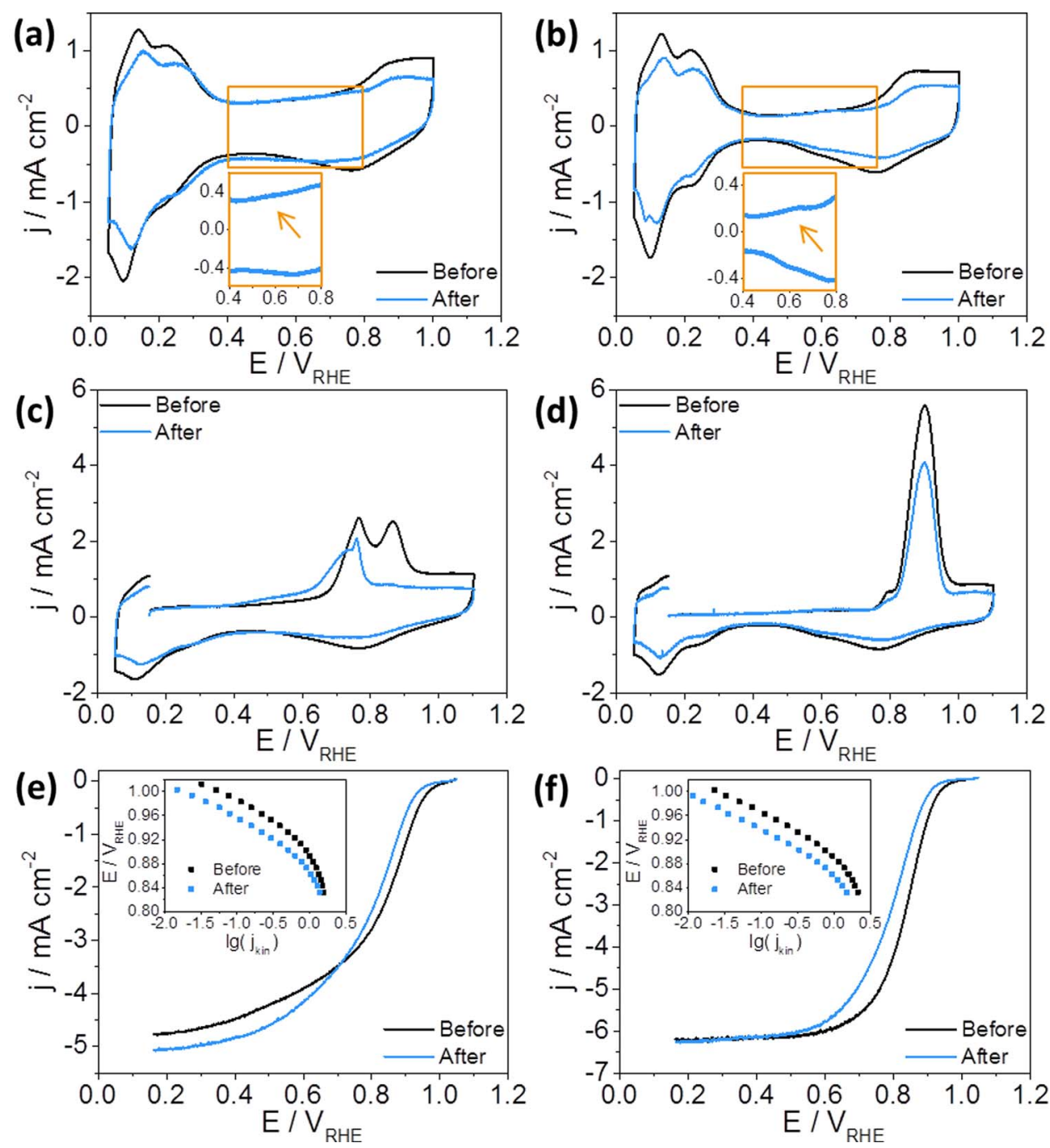

Figure 9. AST of Pt/FTO-rGO and Pt/C. CV curves before and after AST of Pt/FTO-rGO (a) and Pt/C (b) with insets of HQ/Q redox activities after AST, CO stripping curves before and after AST of Pt/FTO-rGO (c) and Pt/C (d), RDE cathodic scans of Pt/FTO-rGO (e) and Pt/C (f) at 1600 rpm with Tafel plot insets before and after AST.

Figure 10a compares CV curves of Pt/FTO-rGO catalyst with those of Pt/C during $\mathrm{CO}$ blocking of the platinum reactions. In case of Pt/FTO-rGO catalyst negligible faradaic peaks in oxidation and reduction area in the range $0.05-0.20 \mathrm{~V}_{\mathrm{RHE}}$ can be surmised indicating remaining free Pt sites for hydrogen deposition. First, a higher double layer capacitive current for $\mathrm{Pt} / \mathrm{FTO}-\mathrm{rGO}$ than $\mathrm{Pt} / \mathrm{C}$ is observed. In our previous study, Pt/TTO-rGO and self-synthesized $\mathrm{Pt} / \mathrm{C}$ were studied in the same way. ${ }^{53}$ With respect to Figure 10a, a high comparability in DL capacitance between Pt/ITO-rGO and Pt/FTO-rGO on the one hand and self-prepared $\mathrm{Pt} / \mathrm{C}$ and commercial $\mathrm{Pt} / \mathrm{C}$ on the other hand is given. Thus, we conclude that nanocomposites with mixed metal oxides and rGO exhibit generally higher double layer capacitances in comparison to conventional carbon black.

Second, Figure 10a shows that the double layer capacitive currents of Pt/FTO-rGO and Pt/C are almost unchanged after the stability test. The $\mathrm{c}_{\mathrm{DL}}$-ratios before and after AST in Figure $10 \mathrm{~b}$ are close to
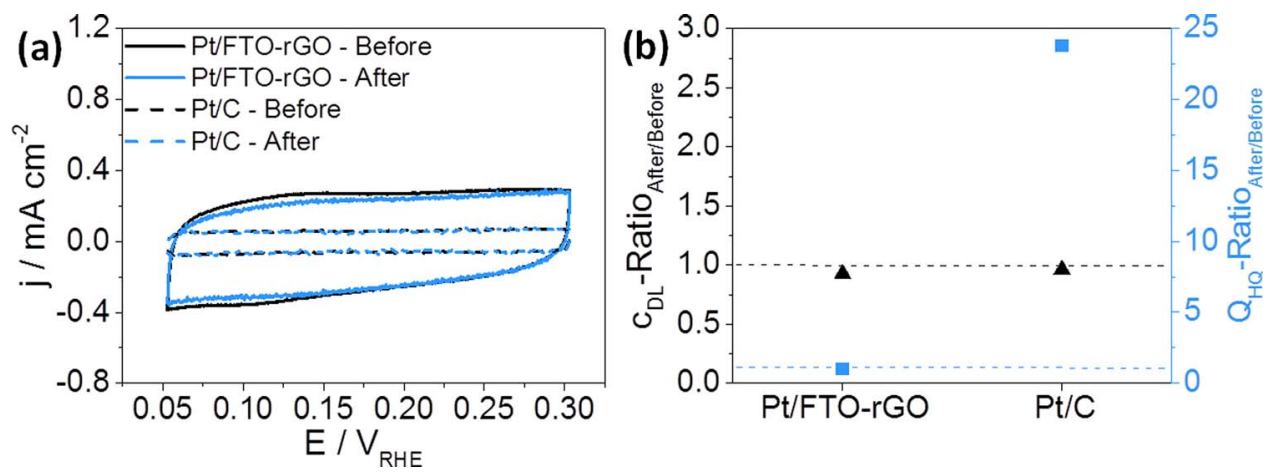

Figure 10. CV curves with adsorbed $\mathrm{CO}$ before and after AST (a) and $\mathrm{QHQ}_{\mathrm{H}}$ - and $\mathrm{C}_{\mathrm{DL}}$-ratios before and after AST (b). 


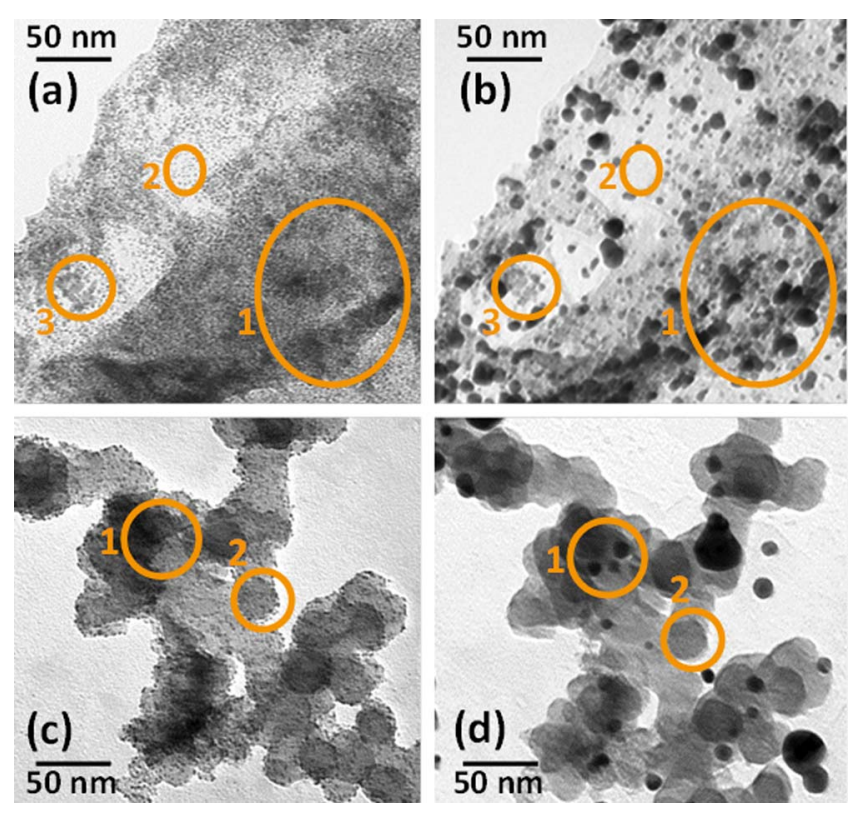

Figure 11. IL-TEM of Pt/FTO-rGO before (a) and after stress test (b) and of $\mathrm{Pt} / \mathrm{C}$ before (c) and after stress test (d); Pt agglomeration marked with $1, \mathrm{Pt}$ disappearance marked with 2 and FTO particles marked with 3 .

one and demonstrate very stable $\mathrm{c}_{\mathrm{DL}}$ for Pt/FTO-rGO as well as for commercial $\mathrm{Pt} / \mathrm{C}$. The comparison with self-prepared $\mathrm{Pt} / \mathrm{C}$ from our previous study ${ }^{53}$ revealed an increased DL capacitance by a factor of 2.6. Although self-prepared $\mathrm{Pt} / \mathrm{C}$ and commercial $\mathrm{Pt} / \mathrm{C}$ contain very similar components, different changes in DL capacitance caused by durability testing are observed.

Regarding the HQ/Q analysis, we observe no appropriate signal around 0.6 $\mathrm{V}_{\mathrm{RHE}}$ in case of Pt/FTO-rGO. The CV curves in Figure $9 \mathrm{a}$ show the absence of $\mathrm{HQ} / \mathrm{Q}$ redox activity before and after potential cycling. In consequence, the $\mathrm{QHQ}_{\mathrm{HQ}}$-ratio of $\mathrm{Pt} / \mathrm{FTO}-\mathrm{rGO}$ in Figure $10 \mathrm{~b}$ is one. Because the presence of HQ/Q functionalities in reduced graphene oxide is known, ${ }^{28,53,77} \mathrm{HQ} / \mathrm{Q}$ redox activity might be suppressed by FTO and Pt anchoring on rGO surface. The comparison of Pt/FTO-rGO and Pt/C in Figure $10 \mathrm{~b}$ reveals a growth of $\mathrm{Q}_{\mathrm{HQ}}$ by a factor close to 25 for commercial $\mathrm{Pt} / \mathrm{C}$. This implies a higher electrochemical stability of the FTO-rGO than commonly used carbon black under our test conditions for PEMFC application.

Additionally to the electrochemical measurements, IL-TEM was carried out. The same stress testing with 1000 potential cycles was done to achieve a high comparability with previous electrochemical results. In Figure 11, the IL-TEM images of Pt/FTO-rGO and Pt/C before and after the stability test are compared. Carbon corrosion is not investigated due to limited resolution of TEM and the possibility of mechanical position changes of support particles on the grid. Furthermore, the exposure to AST causes instabilities of the gold grid at higher potentials (redox activity of $\mathrm{Au} / \mathrm{Au}^{3+}$ with standard potential of $1.36 \mathrm{~V}) .^{78,79}$ Nevertheless, IL-TEM visualizes in Figure 11 strong formation of $\mathrm{Pt}$ agglomerates (marked with 1) and Pt disappearance due to detachment and dissolution (marked with 2) for both catalysts. These degradation processes are clearly assignable to the loss of electrochemical active Pt surface and reduced ORR activity in Figure 9. In other studies, Pt particle growth at potentials between 0.4 $1.4 \mathrm{~V}_{\mathrm{RHE}}$ has also been observed. ${ }^{79,80}$ Moreover, we see unchanged FTO particles (marked with 3) in case of Pt/FTO-rGO after stress testing. This finding demonstrates the stability of fluorine-doped tin (IV) oxide during potential cycling up to $1.47 \mathrm{~V}_{\mathrm{RHE}}$ and goes along with only negligible changes in double layer capacitance of Pt/FTO$\mathrm{rGO}$ and amounts of hydroquinone/quinone species on $\mathrm{rGO}$ surface in Figure 10b.

\section{Conclusions}

The nanocomposite of fluorine-doped tin (IV) oxide and rGO was studied for its application as Pt catalyst support for PEMFC application. HR-TEM analysis with EDS showed dispersed platinum nanoparticles on FTO and rGO with Pt anchoring at FTO-rGO interfaces. Although the electrochemical active Pt surface was lower, the mass and specific ORR activity was larger for Pt/FTO-rGO compared to commonly used Pt on carbon black. Moreover, $\mathrm{CO}$ stripping experiments showed lower $\mathrm{CO}$ binding strength on Pt/FTO-rGO, suggesting higher CO tolerances. Durability testing in terms of potential cycling between 0.05-1.47 $\mathrm{V}_{\mathrm{RHE}}$ resulted in comparable losses of ECSA and ORR activity compared to Pt/C. Pt/FTO-rGO catalyst competes with commercial Pt on carbon black regarding electrochemical stability.

With focus on the support material, stable FTO particles were observed by identical location TEM and unchanged HQ/Q amounts and double layer capacitance in case of Pt/FTO-rGO were revealed by cyclic voltammetry. In contrast, $\mathrm{Pt} / \mathrm{C}$ showed significant increase in HQ/Q functionalities so that FTO-rGO presents the more stable substrate in this study. In view of meeting the stability criterion of low carbon corrosion for PEMFC application, we propose the further study of the FTO-rGO material in membrane-electrode-assemblies under real FC conditions.

\section{Acknowledgments}

The funding by the German Federal Ministry for Economic Affairs in the framework of the project QUALIFIX is greatly appreciated.

\section{ORCID}

Dana Schonvogel (D) https://orcid.org/0000-0002-2485-740X

Peter Wagner (B) https://orcid.org/0000-0002-5644-9881

\section{References}

1. A. Chandan, M. Hattenberger, A. El-kharouf, S. Du, A. Dhir, V. Self, B. G. Pollet, A. Ingram, and W. Bujalski, J. Power Sources, 231(0), 264 (2013).

2. R. Borup, J. Meyers, B. Pivovar, Y. S. Kim, R. Mukundan, N. Garland, D. Myers, M. Wilson, F. Garzon, D. Wood, P. Zelenay, K. More, K. Stroh, T. Zawodzinski, J. Boncella, J. E. McGrath, M. Inaba, K. Miyatake, M. Hori, K. Ota, Z. Ogumi, S. Miyata, A. Nishikata, Z. Siroma, Y. Uchimoto, K. Yasuda, K.-I. Kimijima, and N. Iwashita, Chem. Rev., 107(10), 3904 (2007).

3. B. Millington, S. Du, and B. G. Pollet, J. Power Sources, 196(21), 9013 (2011).

4. Y. Shao-Horn, W. C. Sheng, S. Chen, P. J. Ferreira, E. F. Holby, and D. Morgan, Top. Catal., 46(3-4), 285 (2007).

5. S. Galbiati, A. Baricci, A. Casalegno, and R. Marchesi, Int. J. Hydrogen Energy, 38(15), 6469 (2013)

6. M. P. Rodgers, L. J. Bonville, H. R. Kunz, D. K. Slattery, and J. M. Fenton, Chem. Rev., 112(11), 6075 (2012)

7. J. Kim, J. Lee, and Y. Tak, J. Power Sources, 192(2), 674 (2009).

8. Bandlamudi, Vol. PhD. Universität Duisburg-Essen, Duisburg-Essen, 2011.

9. G. De Moor, C. Bas, F. Lesage, A. S. Danerol, E. Claude, E. Rossinot, M. Paris, L. Flandin, and N. D. Alberola, J. Appl. Polym. Sci., 120(6), 3501 (2011).

10. P. T. Yu, Z. Liu, and R. Makharia, J. Electrochem. Soc., 160(6), F645 (2013).

11. A. Riese, D. Banham, S. Ye, and X. Sun, J. Electrochem. Soc., 162(7), F783 (2015).

12. K. Sasaki, M. Shao, and R. Adzic, in Polymer Electrolyte Fuel Cell Durability, F. N. Büchi, M. Inaba, and T. J. Schmidt, eds., p. 7, Springer New York, (2009).

13. A. Ghosh, S. Basu, and A. Verma, Fuel Cells, 13(3), 355 (2013).

14. A. Marinkas, R. Hempelmann, A. Heinzel, V. Peinecke, I. Radev, and H. Natter, $J$ Power Sources, 295, 79 (2015).

15. J. Liu, D. Takeshi, K. Sasaki, and S. M. Lyth, Fuel Cells, 14(5), 728 (2014).

16. K. Nagasawa, S. Takao, K. Higashi, S.-I. Nagamatsu, G. Samjeske, Y. Imaizumi, O. Sekizawa, T. Yamamoto, T. Uruga, and Y. Iwasawa, Phys. Chem. Chem. Phys., 16(21), 10075 (2014).

17. W. Sheng, S. Woo Lee, E. J. Crumlin, S. Chen, and Y. Shao-Horn, J. Electrochem. Soc., 158(11), B1398 (2011).

18. Y. Shao, S. Zhang, C. Wang, Z. Nie, J. Liu, Y. Wang, and Y. Lin, J. Power Sources, 195(15), 4600 (2010).

19. S. Eigler and A. Hirsch, Angew. Chem. Int. Ed., 53(30), 7720 (2014).

20. M. Liu, R. Zhang, and W. Chen, Chem. Rev., 114(10), 5117 (2014).

21. Y. Liu and W. E. Mustain, Electrochim. Acta, 115, 116 (2014).

22. S.-Y. Huang, P. Ganesan, S. Park, and B. N. Popov, J. Am. Chem. Soc., 131(39), 13898 (2009).

23. Y. Liu and W. E. Mustain, J. Am. Chem. Soc., 135(2), 530 (2013). 
24. H. Schmies, A. Bergmann, J. Drnec, G. Wang, D. Teschner, S. Kühl, D. J. S. Sandbeck, S. Cherevko, M. Gocyla, M. Shviro, M. Heggen, V. Ramani, R. E. Dunin-Borkowski, K. J. J. Mayrhofer, and P. Strasser, Adv. Energy Mater. 1701663-n/a (2018).

25. E. Fabbri, A. Rabis, Y. Chino, M. Uchida, and T. J. Schmidt, Electrochem. Commun., 83(Supplement C), 90 (2017).

26. K. Kakinuma, Y. Chino, Y. Senoo, M. Uchida, T. Kamino, H. Uchida, S. Deki, and M. Watanabe, Electrochim. Acta, 110, 316 (2013).

27. Y. Takabatake, Z. Noda, S. M. Lyth, A. Hayashi, and K. Sasaki, Int. J. Hydrogen Energy, 39(10), 5074 (2014)

28. R. Kou, Y. Shao, D. Mei, Z. Nie, D. Wang, C. Wang, V. V. Viswanathan, S. Park, I. A. Aksay, Y. Lin, Y. Wang, and J. Liu, J. Am. Chem. Soc., 133(8), 2541 (2011).

29. T. Seibel, in "Fachbereich Chemie, Pharmazie und Geowissenschaften,", Vol. PhD. Johannes Gutenberg-Universität Mainz, Mainz, Germany, 2007.

30. H. Xu, L. Shi, Z. Wang, J. Liu, J. Zhu, Y. Zhao, M. Zhang, and S. Yuan, ACS Appl. Mater. Interfaces, 7(49), 27486 (2015).

31. D.-J. Guo and Z.-H. Jing, J. Colloid Interface Sci., 359(1), 257 (2011)

32. S. Yang, Y. Huang, W. Zhu, B. Deng, H. Wang, Z. Zhang, P. Bao, and G. Wang, Int. J. Hydrogen Energy, 39(27), 15063 (2014).

33. S. Ratso, I. Kruusenberg, M. Vikkisk, U. Joost, E. Shulga, I. Kink, T. Kallio, and K. Tammeveski, Carbon, 73(0), 361 (2014).

34. R. Imran Jafri, N. Rajalakshmi, and S. Ramaprabhu, J. Mater. Chem., 20(34), 7114 (2010).

35. S. Neumann, S. Grotheer, J. Tielke, I. Schrader, J. Quinson, A. Zana, M. Oezaslan, M. Arenz, and S. Kunz, J. Mater. Chem. A, 5(13), 6140 (2017).

36. Y. Wang, J. Ren, K. Deng, L. Gui, and Y. Tang, Chem. Mater, 12(6), 1622 (2000).

37. J. Speder, L. Altmann, M. Roefzaad, M. Baumer, J. J. K. Kirkensgaard, K. Mortensen, and M. Arenz, Phys. Chem. Chem. Phys., 15(10), 3602 (2013).

38. M. J. Larsen, I. Jiménez Morales, S. Cavaliere, J. Zajac, D. J. Jones, J. Rozière, L. Kaluža, D. Gulková, and M. Odgaard, Int. J. Hydrogen Energy, 42(10), 7166 (2017).

39. P. S. Fernández, D. S. Ferreira, C. A. Martins, H. E. Troiani, G. A. Camara, and M. E. Martins, Electrochim. Acta, 98, 25 (2013).

40. R. B. de Lima, V. Paganin, T. Iwasita, and W. Vielstich, Electrochim. Acta, 49(1), 85 (2003).

41. C. He, S. Desai, G. Brown, and S. Bollepalli, Electrochem. Soc. Interface, 14(3), 41 (2005).

42. K. Balasubramanian and M. Burghard, Chem. unserer Zeit, 45(4), 240 (2011).

43. P. Kundu, C. Nethravathi, P. A. Deshpande, M. Rajamathi, G. Madras, and N. Ravishankar, Chem. Mater., 23(11), 2772 (2011).

44. S. Wu, S. Yuan, L. Shi, Y. Zhao, and J. Fang, J. Colloid Interface Sci., 346(1), 12 (2010).

45. F. Zhou, S. J. Andreasen, S. K. Kær, and D. Yu, Int. J. Hydrogen Energy, 40(6), 2833 (2015).

46. J. H. Jung, H. J. Park, J. Kim, and S. H. Hur, J. Power Sources, 248, 1156 (2014).

47. T. Engl, K. E. Waltar, L. Gubler, and T. J. Schmidt, J. Electrochem. Soc., 161(4), F500 (2014).

48. K. Jukk, N. Kongi, P. Rauwel, L. Matisen, and K. Tammeveski, Electrocatalysis, 7(5), 428 (2016).

49. K. J. J. Mayrhofer, D. Strmcnik, B. B. Blizanac, V. Stamenkovic, M. Arenz, and N. M. Markovic, Electrochim. Acta, 53, 3181 (2008).

50. Q.-S. Chen, J. Solla-Gullón, S.-G. Sun, and J. M. Feliu, Electrochim. Acta, 55(27), 7982 (2010).

51. P. Urchaga, S. Baranton, C. Coutanceau, and G. Jerkiewicz, Langmuir, 28(7), 3658 (2012).
52. B. Ruiz Camacho, C. Morais, M. A. Valenzuela, and N. Alonso-Vante, Catal. Today, 202, 36 (2013).

53. D. Schonvogel, J. Hülstede, P. Wagner, I. Kruusenberg, K. Tammeveski, A. Dyck, C. Agert, and M. Wark, J. Electrochem. Soc., 164(9), F995 (2017).

54. S. Taylor, E. Fabbri, P. Levecque, T. J. Schmidt, and O. Conrad, Electrocatalysis, 1 (2016).

55. T. Matsui, K. Fujiwara, T. Okanishi, R. Kikuchi, T. Takeguchi, and K. Eguchi, J. Power Sources, 155(2), 152 (2006).

56. S. Stevanović, D. Tripković, V. Tripković, D. Minić, A. Gavrilović, A. Tripković, and V. M. Jovanović, J. Phys. Chem. C, 118(1), 278 (2014).

57. J. Lobato, H. Zamora, J. Plaza, P. Cañizares, and M. A. Rodrigo, Appl. Catal. B Environ., 198, 516 (2016).

58. N. R. Elezović, B. M. Babić, V. R. Radmilović, and N. V. Krstajić, J. Electrochem. Soc., 160(10), F1151 (2013).

59. K. Kakinuma, M. Uchida, T. Kamino, H. Uchida, and M. Watanabe, Electrochim. Acta, 56(7), 2881 (2011).

60. B. Ruiz-Camacho, J. H. Martínez-González, R. G. González-Huerta, and M. Tufiño-Velázquez, Int. J. Hydrogen Energy, 39(29), 16731 (2014).

61. K. Tiido, N. Alexeyeva, M. Couillard, C. Bock, B. R. MacDougall, and K. Tammeveski, Electrochim. Acta, 107(0), 509 (2013).

62. N. M. Markovioc, H. A. Gasteiger, and P. N. Ross Jr., J. Phys. Chem., 100(16), 6715 (1996).

63. U. A. Paulus, T. J. Schmidt, H. A. Gasteiger, and R. J. Behm, J. Electroanal. Chem., 495(2), 134 (2001).

64. K. Shinozaki, J. W. Zack, S. Pylypenko, B. S. Pivovar, and S. S. Kocha, J. Electrochem. Soc., 162(12), F1384 (2015).

65. M. Özaslan, in "Fakultät II - Mathematik und Naturwissenschaften,", Vol. PhD, p. 214. Technischen Universität Berlin, Berlin, 2012.

66. C. Wang, H. Daimon, T. Onodera, T. Koda, and S. Sun, Angew. Chem., 120(19), 3644 (2008).

67. M. Peuckert, T. Yoneda, R. A. D. Betta, and M. Boudart, J. Electrochem. Soc., 133(5), 944 (1986).

68. K. Kinoshita, J. Electrochem. Soc., 137(3), 845 (1990).

69. S. S. Kocha, K. Shinozaki, J. W. Zack, D. J. Myers, N. N. Kariuki, T. Nowicki, V. Stamenkovic, Y. Kang, D. Li, and D. Papageorgopoulos, Electrocatalysis, 8(4), 366 (2017).

70. M. Nesselberger, S. Ashton, J. C. Meier, I. Katsounaros, K. J. J. Mayrhofer, and M. Arenz, J. Am. Chem. Soc., 133(43), 17428 (2011).

71. S. Taylor, E. Fabbri, P. Levecque, T. J. Schmidt, and O. Conrad, Electrocatalysis, 7(4), 287 (2016)

72. K. Jukk, J. Kozlova, P. Ritslaid, V. Sammelselg, N. Alexeyeva, and K. Tammeveski, J. Electroanal. Chem., 708, 31 (2013).

73. M. Yin, J. Xu, Q. Li, J. O. Jensen, Y. Huang, L. N. Cleemann, N. J. Bjerrum, and W. Xing, Appl. Catal. B - Environ., 144, 112 (2014).

74. F. Hasche, M. Oezaslan, and P. Strasser, Phys. Chem. Chem. Phys., 12(46), 15251 (2010).

75. T. Kinumoto, N. Eguchi, M. Matsuoka, T. Tsumura, and M. Toyoda, ECS Trans., 50(2), 1701 (2013)

76. F. Maillard, M. Eikerling, O. V. Cherstiouk, S. Schreier, E. Savinova, and U. Stimming, Faraday Discuss., 125, 357 (2004).

77. Y. Li, Y. Li, E. Zhu, T. McLouth, C.-Y. Chiu, X. Huang, and Y. Huang, J. Am. Chem. Soc., 134(30), 12326 (2012).

78. A. J. Bard, R. Parsons, and J. Jordan, Standard Potentials in Aqueous Solution, CRC Press (1985).

79. K. Schlögl, K. J. J. Mayrhofer, M. Hanzlik, and M. Arenz, J. Electroanal. Chem., 662, 355 (2011).

80. A. Zana, J. Speder, M. Roefzaad, L. Altmann, M. Bäumer, and M. Arenz, J. Electrochem. Soc., 160(6), F608 (2013). 